\title{
StreamFlow 1.0: an extension to the spatially distributed snow model Alpine3D for hydrological modelling and deterministic stream temperature prediction
}

\author{
Aurélien Gallice $^{1}$, Mathias Bavay ${ }^{2}$, Tristan Brauchli ${ }^{1}$, Francesco Comola ${ }^{1}$, Michael Lehning ${ }^{1,2}$, and Hendrik Huwald ${ }^{1}$ \\ ${ }^{1}$ School of Architecture, Civil and Environmental Engineering (ENAC), École Polytechnique Fédérale de Lausanne (EPFL), \\ Lausanne, Switzerland \\ ${ }^{2}$ SLF, WSL Institute for Snow and Avalanche Research, 7260 Davos, Switzerland
}

Correspondence to: Mathias Bavay (bavay@slf.ch)

Received: 29 June 2016 - Published in Geosci. Model Dev. Discuss.: 10 August 2016

Revised: 7 November 2016 - Accepted: 23 November 2016 - Published: 21 December 2016

\begin{abstract}
Climate change is expected to strongly impact the hydrological and thermal regimes of Alpine rivers within the coming decades. In this context, the development of hydrological models accounting for the specific dynamics of Alpine catchments appears as one of the promising approaches to reduce our uncertainty of future mountain hydrology. This paper describes the improvements brought to StreamFlow, an existing model for hydrological and stream temperature prediction built as an external extension to the physically based snow model Alpine3D. StreamFlow's source code has been entirely written anew, taking advantage of object-oriented programming to significantly improve its structure and ease the implementation of future developments. The source code is now publicly available online, along with a complete documentation. A special emphasis has been put on modularity during the re-implementation of StreamFlow, so that many model aspects can be represented using different alternatives. For example, several options are now available to model the advection of water within the stream. This allows for an easy and fast comparison between different approaches and helps in defining more reliable uncertainty estimates of the model forecasts. In particular, a case study in a Swiss Alpine catchment reveals that the stream temperature predictions are particularly sensitive to the approach used to model the temperature of subsurface flow, a fact which has been poorly reported in the literature to date. Based on the case study, StreamFlow is shown to reproduce hourly mean discharge with a Nash-Sutcliffe efficiency
\end{abstract}

(NSE) of 0.82 and hourly mean temperature with a NSE of 0.78 .

\section{Introduction}

Mountainous areas play a major role in hydrology by accumulating precipitation as snow and ice during the winter and redistributing it as melt water during spring and summer. Downstream areas hereby receive larger amounts of water during the hot season, when demand - especially in terms of agriculture - is highest. In fact, Viviroli et al. (2011) estimate that more than $40 \%$ of the world's mountainous regions provide an important supply for low-land water use. Accordingly, more than one-sixth of the world's population is currently living in areas depending on snow melt for their water supply (Barnett et al., 2005). Apart from its relevance for downstream areas, mountain hydrology also strongly impacts hydropower production (e.g. Schaefli et al., 2007; Finger et al., 2012; Majone et al., 2016), determines the habitat suitability of numerous aquatic organisms (e.g. Short and Ward, 1980; Hari et al., 2006; Wilhelm et al., 2015; Padilla et al., 2015) and even plays a noticeable role in the global emission of carbon dioxide into the atmosphere (Butman and Raymond, 2011; Raymond et al., 2013).

Mountainous environments have recently been identified as being especially sensitive to climate change (e.g. Barnett et al., 2005; Stewart et al., 2005; Viviroli et al., 2011). In particular, winter air temperature over the last 70 years has been 
observed to increase by more than twice the global mean in the European Alps (Beniston, 2012), and this trend is forecasted to remain unchanged in the next decades (Kormann et al., 2015b). Rising air temperature will be responsible for less precipitation falling as snow in winter and an earlier onset of snow melt in spring (e.g. Barnett et al., 2005; Bavay et al., 2009, 2013). As a consequence, the spring freshet will occur earlier in the season and, assuming mean annual precipitation to remain constant, will also have a reduced magnitude (e.g. Stewart et al., 2005; Kormann et al., 2015a, b, to name just a few). Some studies predict an increase in winter precipitation, which could at least partially compensate for the decreased fraction of solid precipitation and sustain the spring freshet close to its actual level (Schaefli et al., 2007; Beniston, 2012; Finger et al., 2012; Fatichi et al., 2015). Autumn and winter stream discharge is expected to increase in magnitude and variability as a result of the higher fraction of precipitation falling as rain, which might result in greater flood risks in winter (Barnett et al., 2005; Bavay et al., 2009; Finger et al., 2012; Beniston, 2012). Summer discharge will likely be much reduced and the drought risks therefore more pronounced, at least in the watersheds with little or no glacier cover (Schaefli et al., 2007; Stewart et al., 2015). In glaciated catchments, increased summer ice melt might (over)compensate for the reduced snow melt on an annual average basis (Bavay et al., 2013; Kormann et al., 2015a). This compensation is, however, expected to last only until the glaciers have shrunk to the point where ice melt discharge starts to decrease as well, a phenomenon which has already been observed in some parts of the world (see, e.g. studies mentioned in Kormann et al., 2015a). In summary, the hydrological regimes of many mountainous catchments are forecasted to shift from glacio-nival and nival signatures to nivo-pluvial or even pluvial regimes (Aschwanden and Weingartner, 1985; Beniston, 2012).

As a result of the changes in climate and hydrological regime, the thermal regime of the mountain streams will change as well in the coming decades (e.g. Morrison et al., 2002; Null et al., 2013; Ficklin et al., 2014; Stewart et al., 2015). Due to the strong correlation between stream and air temperatures (e.g. Mohseni et al., 1998; Caissie, 2006), the increase in air temperature is expected to be associated with globally higher stream temperatures over the year (e.g. Ferrari et al., 2007; Ficklin et al., 2012). The increase in mean annual precipitation predicted by some studies will only slightly mitigate this temperature rise through an increase of the mean annual discharge - and hence the heat capacity - of the streams (Ficklin et al., 2012, 2014). The reduction of the spring freshet will diminish the buffering effect of snowmelt on stream temperature, hereby leading to larger stream temperature increases in spring (Ficklin et al., 2014). Similarly, lower summer flows in little-glaciated catchments are likely to result in increased mean summer stream temperature and more frequent extreme temperature events (Stewart et al., 2005; Null et al., 2013). All these predictions support the hypothesis that stream temperature will respond in a nonlinear way to the air temperature rise.

The climate-change-induced modifications of the hydrological and thermal regimes of alpine streams are expected to strongly impact their ecology. The forthcoming air temperature rise will lead to a modification of the riparian vegetation, which in turn will affect the stream ecosystem (Hauer et al., 1997). The higher stream temperatures will also have consequences on the cold-water fish species encountered in mountain streams, whose fry emergence date (Elliott and Elliott, 2010), growth rate (Hari et al., 2006) and death rate (Wehrly et al., 2007) are all mostly dependent on stream temperature. Future increases in stream temperature are expected to result in a shift of the suitable habitat for such species to higher elevations, where dams and other physical barriers might limit their migration and result in a reduction of their habitat (Hauer et al., 1997; Hari et al., 2006). However, recent studies indicate that this habitat loss may be less important than was thought until now, since the high elevation gradients in mountainous areas imply only a small reduction of fish territory per degree increase in stream temperature (e.g. Isaak et al., 2016).

The modification of the stream ecology is only one example of the consequences of climate change on mountain streams. In order to better evaluate and predict these consequences, numerous numerical models have been developed over the last decades. Most of them concentrate either on the prediction of discharge (e.g. Grillakis et al., 2010; Bürger et al., 2011; Schaefli et al., 2014; Ragettli et al., 2014) or water temperature (e.g. Caldwell et al., 2013; Tung et al., 2014; Hébert et al., 2015; Toffolon and Piccolroaz, 2015), but few are able to simulate the two at the same time (e.g. Loinaz et al., 2013; MacDonald et al., 2014; Comola et al., 2015). Regarding the models predicting only discharge, they can be classified - among other possibilities and in order of increasing spatial resolution - either as lumped, semi-distributed or fully distributed (e.g. Khakbaz et al., 2012). Lumped models are often based on empirical equations and only allow for the computation of stream discharge at the catchment outlet. Fully distributed models, on the other hand, typically solve the full mass and momentum conservation equations, but require extensive computational resources (e.g. Beven, 2012). As a trade-off between the two approaches, semidistributed models have become quite popular over the last decades, since they can be applied over large areas while at the same time be able to account for subcatchment characteristics (Khakbaz et al., 2012; Beven, 2012). An equivalent sort of classification is commonly applied to stream temperature models, which are usually separated into statistical and mechanistic models (Caissie, 2006). Statistical models require less input data and are usually easier to use, but their lack of physical basis is often seen as a limit to the validity of their predictions in the context of climate change studies (e.g. Piccolroaz et al., 2016). On the contrary, more credit is generally given to the long-term forecasts of the deterministic 
Table 1. List of semi-distributed hydrological models which simulate both stream discharge and stream temperature and have been reviewed in the context of the present study.

\begin{tabular}{llll}
\hline Model name & Publication & Time resolution & Target geographic location \\
\hline LARSIM-WT & Haag and Luce (2008) & hourly, daily & small to large river basins \\
MODEL-Y & Sullivan et al. (1990) & hourly & $\begin{array}{l}\text { forested catchments } \\
\text { forested catchments }\end{array}$ \\
SHADE-HSPF & Chen et al. (1998) & hourly & laily \\
VIC-RMB & van Vliet et al. (2012) & dailyer basins \\
CEQUEAU & St-Hilaire et al. (2000) & hourly, daily & forested catchments in Canada \\
UBC & Morrison et al. (2002) & hourly & large river basins \\
GISS GCM & Ferrari et al. (2007) & monthly & large river basins \\
SWAT & Ficklin et al. (2012) & daily, monthly & medium- to large-scale catchments \\
MIKE-SHE MIKE11 & Loinaz et al. (2013) & hourly & medium-scale catchments \\
WEAP21-RTEMP & Null et al. (2013) & weekly & large river basins \\
DHSVM & Sun et al. (2015) & hourly & small forested or urban catchments \\
GENESYS & MacDonald et al. (2014) & hourly & mountainous catchments \\
PCR-GLOBWB & van Beek et al. (2012) & daily & large river basins \\
\hline
\end{tabular}

stream temperature models, although their accuracy is about the same - if not worse (Ficklin et al., 2014) - than that of the statistical models. It should be mentioned that an intermediate sort of model, referred to as hybrid, has recently been developed (Gallice et al., 2015; Toffolon and Piccolroaz, 2015) and shown by Piccolroaz et al. (2016) to be suitable for climate change studies.

As opposed to the separate simulation of discharge and stream temperature, the coupled modelling of the two offers new perspectives to investigate the effects of climate change on mountain hydrology (e.g. Ficklin et al., 2014). For example, the variations of temperature resulting from the fluctuations in discharge can be better resolved (e.g. van Vliet et al., 2012; Null et al., 2013). The use of both discharge and temperature measurement data to calibrate the model has also been shown by Comola et al. (2015) to improve the quality of the simulation. Surprisingly, only a few coupled hydrothermal models have been developed to date (see Table 1), probably as a result of the rather small size of the scientific community involved in stream temperature research. Out of the 13 semi-distributed coupled models listed in Table 1, only 1 was specifically developed for mountainous environments (MacDonald et al., 2014). The other ones were either tailored to large-scale applications (Morrison et al., 2002; Ferrari et al., 2007; van Vliet et al., 2012; van Beek et al., 2012; Null et al., 2013) or aimed at being used over low-altitude catchments (e.g. Sullivan et al., 1990; Chen et al., 1998; Haag and Luce, 2008), except for the model of Sun et al. (2015) which has been tested over Alpine watersheds. In addition, all of these models simulate the snowpack energy balance using a more or less simplified approach, most of them relying on the degree-day method (e.g. van Beek et al., 2012; Null et al., 2013; MacDonald et al., 2014).

The present study aims at presenting the improvements brought to the semi-distributed model recently developed by Comola et al. (2015) for coupled streamflow discharge and temperature simulations. This model, referred to as StreamFlow in the following, was specifically developed for high Alpine environments, as it builds upon the detailed snow model Alpine3D (Lehning et al., 2006). It was decided to entirely rewrite the code of Comola et al. so as to fully exploit the advantages offered by object-oriented programming in terms of flexibility and code structure. In particular, the new model is much more modular, allowing for various components of the hydrological cycle to be modelled using different approaches. Some of these approaches which were not present in the original model of Comola et al. have been implemented, hereby offering a wider range of modelling possibilities to the end user. In its present form, the model application is restricted to catchments located above the tree line or with little to no vegetation cover along the stream, due to the absence of a proper riparian vegetation module. This constraint should be relaxed in the very near future with the next version of StreamFlow. The mass- and energy-balance equations implemented in the model are detailed in Sect. 2, and the new code structure in Sect. 3. The model is applied to a case study in Sect. 4 in order to demonstrate some of its features and provide an assessment of its accuracy. Conclusions are found in Sect. 5.

\section{Model description}

StreamFlow is built as an independent extension to the spatially distributed snow model Alpine3D (Lehning et al., $2006,2008)$. The latter was developed to study multiple subjects such as the impact of climate change on snow cover (Bavay et al., 2009, 2013), the effect of wind and topography on snow deposition (Mott and Lehning, 2010; Mott et al., 2014) or the sublimation of drifting snow (Groot Zwaaftink et al., 2013). Alpine3D operates on a regular mesh grid and essentially runs the one-dimensional Snowpack model over each grid cell independently. Snowpack computes the time 

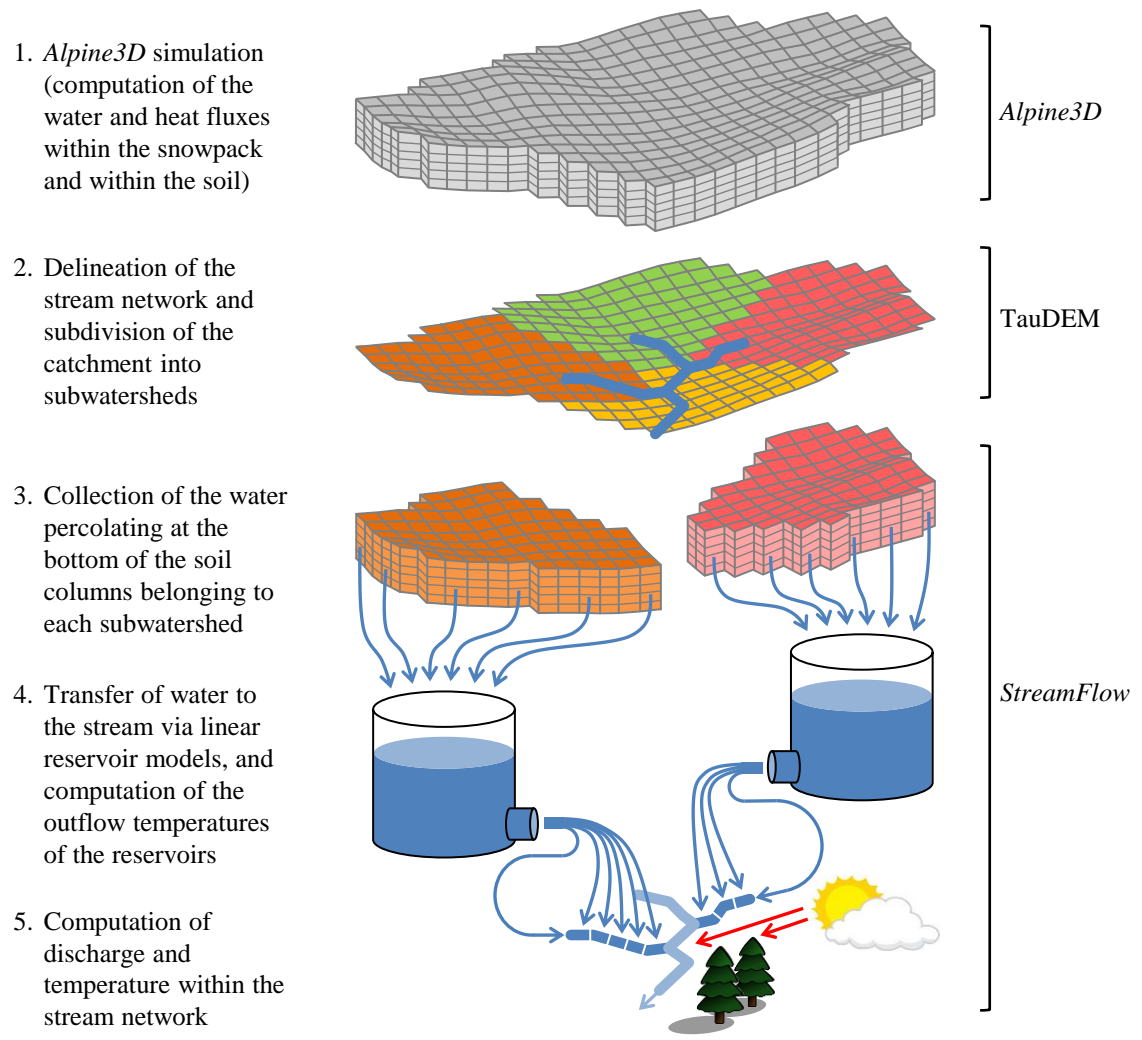

Figure 1. Schematic representation of the work flow in StreamFlow. Note that the first two steps are not performed in StreamFlow itself but in Alpine3D and with the help of TauDEM, respectively.

evolution of the vertical snow profile, as well as the vertical profiles of soil moisture and soil temperature (Bartelt and Lehning, 2002; Lehning et al., 2002b, a). It accounts for the canopy layer (Gouttevin et al., 2015) and can simulate the vertical water transport using either the Richards equation or a simple bucket scheme (Wever et al., 2014, 2015).

StreamFlow is implemented as a semi-distributed model, i.e. based on the subdivision of the catchment into subwatersheds. This subdivision is typically performed using the wellknown tool suite TauDEM (Tarboton, 1997), which extracts both the stream network and its corresponding set of subwatersheds from the digital elevation model (DEM). The stream network is automatically partitioned into so-called "stream reaches", where each reach is uniquely associated with a subwatershed and corresponds to the portion of the stream network which specifically drains the subwatershed in question. It should be stressed that subwatersheds are independent and distinct from each other, i.e. they do not spatially overlap and are considered not to interact from a hydrological point of view. Stream reaches, on the other hand, are connected to each other: the computation of discharge and temperature in a given reach requires the same variables to be computed in its upstream tributaries first.

As schematically represented in Fig. 1, StreamFlow pursues the simulation of the water flow from the point where
Alpine3D stops modelling it. Each subwatershed is approximated in StreamFlow as a linear reservoir. The total percolation rate computed by Alpine3D at the bottom of all the soil columns belonging to a given subwatershed is considered by StreamFlow as the inflow rate into the associated linear reservoir. The latter then computes the discharge and temperature of the subsurface water flux generated by the subwatershed. Note that the term "subsurface water flux" (or, shorter, "subsurface flux") will be used in the remainder of this paper as a generic word representing both the fast and slow components of subsurface flow, which are sometimes referred to as interflow and baseflow in the literature. The subsurface water flux produced by each subwatershed is delivered as lateral inflow to its associated stream reach (see Fig. 1). In other words, the subwatersheds are used in StreamFlow to compute the amount of subsurface water and heat penetrating the stream network. As such, the model is only able to reproduce so-called "gaining streams", as opposed to "losing streams" which would require a mechanism to transfer water from the stream network to the subwatersheds. As a final step, StreamFlow advects water and energy within the stream network down to the catchment outlet point. To this end, discharge and temperature are computed within each stream reach, notably taking the water and heat inflows originating from the upstream reaches and from the subsurface flux into account. 
The different processing steps of StreamFlow are described in more detail below.

\subsection{Subwatershed modelling}

In StreamFlow, the discharge $Q_{\text {subw }}\left(\mathrm{m}^{3} \mathrm{~s}^{-1}\right)$ of the subsurface water flux generated by each subwatershed is computed independently from its temperature $T_{\text {subw }}(\mathrm{K})$. This allows for the different temperature modelling approaches to be combined with every discharge computation alternative.

\subsubsection{Water transfer}

Only the linear reservoir approach developed by Comola et al. (2015) has been implemented so far for the estimation of the subsurface flux discharge, but the modular structure of StreamFlow supports the integration of more complex, physically based algorithms. The approach of Comola et al. represents each subwatershed as two superposed linear reservoirs, the lower one being filled at a maximum inflow rate $R_{\max }\left(\mathrm{m} \mathrm{s}^{-1}\right)$ and the upper one receiving the excess inflow water. The model behaviour is controlled by three user-specified parameters: the mean characteristic residence times $\bar{\tau}_{\text {res,u }}$ (s) and $\bar{\tau}_{\text {res,l }}$ (s) in the upper and lower reservoirs, and $R_{\max }$. The complete mathematical background underlying this approach is detailed in Comola et al. (2015); a summary of the main equations and an explanatory figure can be found in Appendix A. Depending on the approach used to spatially discretize the stream reaches, water flowing out of each subwatershed is either transferred to its associated reach as a whole or partitioned between the different cells composing the stream reach (see below).

\subsubsection{Computation of the subwatershed outflow temperature}

Three alternatives are available in StreamFlow for the estimation of the subsurface flux temperature. The first approach corresponds to the one developed by Comola et al. (2015), which performs a simplified energy balance of subsurface water at the subwatershed scale. Since this method specifically requires the subwatershed outlet discharge to be modelled exactly as in Sect. 2.1.1, it is not compatible with potential future alternatives for modelling the subsurface water flux. It computes the temperature of water stored in each one of the two superposed reservoirs based on the temperature of infiltrating water, taking thermal exchange with the surrounding soil into account. It requires the specification of a parameter, $k_{\text {soil }}(\mathrm{s})$, which corresponds to the characteristic time of thermal diffusion between the water stored in the reservoirs and the soil. The complete description of this technique can be found in Comola et al. (2015) and is also summarized in Appendix A for convenience.

The second method implemented in StreamFlow for the computation of $T_{\text {subw }}$ is adapted from the approach used in the Hydrological Simulation Program-Fortran (HSPF; Bick- (a)

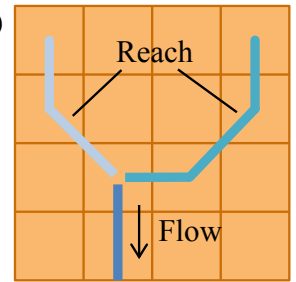

(b)

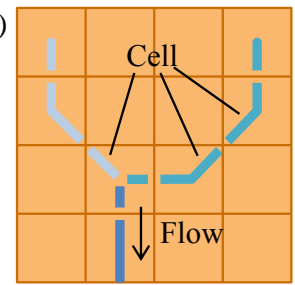

Figure 2. Available methods for spatially discretizing the stream reaches in StreamFlow: (a) the lumped approach, treating each stream reach as a lumped entity, and (b) the discretized approach, subdividing each reach into smaller entities called cells. Each stream reach is represented using a different shade of blue in the figure. The grid shown in brown corresponds to the DEM used by TauDEM to identify the subwatersheds and the stream network.

nell et al., 1997). This technique essentially approximates the time evolution of $T_{\text {subw }}$ by smoothing and adding an offset to the time series of air temperature $T_{\mathrm{a}}(\mathrm{K})$ :

$$
\frac{\mathrm{d} T_{\text {subw }}}{\mathrm{d} t}=\frac{1}{\tau_{\mathrm{HSPF}}}\left(T_{\mathrm{a}}-T_{\text {subw }}+D_{\mathrm{HSPF}}\right) .
$$

In the above equation, $T_{\mathrm{a}}$ is taken as the mean air temperature over the subwatershed as computed by Alpine3D, and the smoothing coefficient $\tau_{\mathrm{HSPF}}$ (s) and the temperature offset $D_{\mathrm{HSPF}}(\mathrm{K})$ can be freely specified by the user. This equation is solved in StreamFlow using a second-order CrankNicolson scheme.

Finally, the third technique for estimating the temperature of the subsurface flux relies on the assumption that infiltrated water is in thermal equilibrium with the surrounding soil matrix. As such, $T_{\text {subw }}$ can be considered to have the same value as the local soil temperature $T_{\text {soil }}$ averaged between the soil surface and a given depth $z_{\mathrm{d}}(\mathrm{m})$. In practice, $T_{\text {subw }}$ is determined at any point along the stream network by identifying the cell of the Alpine3D mesh in which it is located, and then averaging the soil temperature values computed by Alpine3D in this cell down to depth $z_{\mathrm{d}}$. We consider this approach for computing the subsurface flux temperature to be more physically based than the first two presented above. As such, we expect this method to provide better results, except in streams dominated by deep groundwater contributions, since it is less able than the other two methods to simulate an almost constant subsurface flux temperature over the year.

\subsection{Stream network modelling}

As mentioned above, the computation of discharge and temperature within the stream network is based on the subdivision of the latter into reaches. Each reach is uniquely associated with its corresponding subwatershed and is automatically identified by TauDEM based on a geomorphological analysis of the DEM. The stream reaches can be modelled in StreamFlow using two different approaches (see Fig. 2): 
a. The first is a lumped approach, in which each reach is treated as a single entity whose mean water depth, outlet discharge and temperature are to be computed. This method was already implemented by Comola et al. (2015) in the first version of StreamFlow. In this approach, each reach collects the subsurface water flux originating from its associated subwatershed as a whole; no spatial discretization is performed.

b. The second is a discretized approach, which subdivides each reach into smaller spatial units referred to as "cells" in the following. The cells are delineated using the grid pattern of the DEM used by TauDEM to identify the subwatersheds and the stream network (see Fig. 2); as a consequence, all cells do not have the same length within a single reach. This discretization method provides higher spatial resolution than the lumped approach and supports more advanced techniques for water and temperature routing (e.g. the resolution of the shallow water equations). In this approach, the water flowing out of each subwatershed is transferred to the cells of its corresponding stream reach, proportionally to the specific drainage area of each cell.

The different methods available in StreamFlow for instream routing of water and energy are described below.

\subsubsection{Water routing}

Stream discharge can be computed using two different approaches, which can both be used with lumped or discretized reaches. A third approach, namely the shallow water equation solver for the discretized reaches, is currently being developed and should be available in the near future.

The first water routing technique is the same as the one already available in the original version of StreamFlow, namely the instantaneous advection of water down to the catchment outlet. This approach is based on the fact that, in small catchments, the amount of time required for a rain drop to reach the catchment outlet is mostly dominated by the time spent within the hillslopes (see, e.g. Comola et al., 2015). Water depth $h(\mathrm{~m})$ is computed using a power function of discharge $Q\left(\mathrm{~m}^{3} \mathrm{~s}^{-1}\right)$, i.e. $h=\alpha_{h} Q^{\beta_{h}}$, where the coefficients $\alpha_{h}$ and $\beta_{h}$ can be calibrated or specified a priori.

The second approach corresponds to the well-known Muskingum-Cunge technique, shown by Cunge (1969) to be a diffusive-wave approximation of the shallow water equations. StreamFlow implements the modified three-point variable parameter method developed by Ponce and Changanti (1994), which is first-order accurate in time and second-order accurate in space. This method can be used with both lumped and discretized stream reaches. In discretized reaches, it estimates discharge $Q_{i}^{n+1}\left(\mathrm{~m}^{3} \mathrm{~s}^{-1}\right)$ at the outlet of cell $i$ at time $t_{n+1}=t_{n}+\Delta t$ (see, e.g. Tang et al., 1999) as

$Q_{i}^{n+1}=c_{1} Q_{i-1}^{n}+c_{2} Q_{i-1}^{n+1}+c_{3} Q_{i}^{n}$, where $\Delta t$ (s) denotes the time step, $Q_{i-1}^{n}$ the sum of the outlet discharge of cell $i-1$ and the lateral subsurface flow discharge into cell $i$ at time $t_{n}$, and the coefficients $\left\{c_{k}\right\}_{k=1,2,3}(-)$ are computed as

$c_{1}=\frac{k_{i} x_{i}+0.5 \Delta t}{k_{i}\left(1-x_{i}\right)+0.5 \Delta t}$,

$c_{2}=\frac{-k_{i} x_{i}+0.5 \Delta t}{k_{i}\left(1-x_{i}\right)+0.5 \Delta t}$,

$c_{3}=\frac{k_{i}\left(1-x_{i}\right)-0.5 \Delta t}{k_{i}\left(1-x_{i}\right)+0.5 \Delta t}$.

Parameters $k_{i}(\mathrm{~s})$ and $x_{i}(-)$ can be related to hydraulic properties of the stream cell,

$k_{i}=\frac{l_{i}}{c_{\mathrm{r}}}$

$x_{i}=\frac{1}{2} \min \left(1,1-\frac{Q_{\mathrm{r}}}{c_{\mathrm{r}} w S_{0} l_{i}}\right)$,

with $l_{i}(\mathrm{~m})$ denoting the cell length, $w(\mathrm{~m})$ the stream width, $S_{0}(-)$ the local bed slope in cell $i, c_{\mathrm{r}}\left(\mathrm{ms}^{-1}\right)$ a representative wave celerity and $Q_{\mathrm{r}}\left(\mathrm{m}^{3} \mathrm{~s}^{-1}\right)$ a representative discharge. Manning's formula is used to derive $c_{\mathrm{r}}$ from $Q_{\mathrm{r}}$ under the assumption of a rectangular channel cross-section,

$c_{\mathrm{r}}=\frac{5}{3}\left(\frac{S_{0}}{n_{\mathrm{m}}{ }^{2}}\right)^{3 / 10}\left(\frac{Q_{\mathrm{r}}}{w}\right)^{2 / 5}$,

where $n_{\mathrm{m}}\left(\mathrm{s} \mathrm{m}^{-1 / 3}\right)$ is the Manning coefficient, whose value is generally accepted to be within the approximate range 0.03-0.10 for small natural streams (e.g. Phillips and Tadayon, 2006). $Q_{\mathrm{r}}$ is computed as

$Q_{\mathrm{r}}=\frac{Q_{i-1}^{n}+Q_{i-1}^{n+1}+Q_{i}^{n}}{3}$.

Manning's formula is also used to determine the water depth $h_{i}^{n+1}(\mathrm{~m})$ in cell $i$ at time $t_{n+1}$ based on $Q_{i}^{n+1}$ :

$h_{i}^{n+1}=\left(\frac{n_{\mathrm{m}} Q_{i}^{n+1}}{w S_{0}}\right)^{3 / 5}$.

In order to avoid numerical instabilities, the time step $\Delta t$ is chosen according to the recommendations of Tang et al. (1999):

$\max _{i}\left(2 k_{i} x_{i}\right) \leqslant \Delta t \leqslant \min _{i}\left(2 k_{i}\left(1-x_{i}\right)\right)$.

Equation (8) must be verified for all cells belonging to the entire stream network.

When using lumped stream reaches, Eqs. (2)-(8) have to be adapted as follows: $l_{i}$ is to be replaced with the reach length, $S_{0}$ with the average bed slope over the reach and $Q_{i-1}^{n}$ with the sum of the outlet discharge(s) of the upstream reach(es) and the lateral subsurface flow discharge into the 
stream reach at time $t_{n}$. In addition, $Q_{i}^{n}$ and $h_{i}^{n}$ have to be interpreted as the outlet discharge and mean water depth in the reach at time $t_{n}$.

Both water routing techniques assume the stream width $w$ to be spatially constant within each reach. Several methods are available for the computation of $w$, such as a linear function of the total area drained by the stream reach. The possibility is also offered to set $w$ as a power-law function of the reach outlet discharge, hereby making $w$ time dependent. Each of these methods requires the specification of two parameters, which should be set prior to the StreamFlow simulation.

\subsubsection{Stream energy-balance computation}

The computation of in-stream temperature assumes a constant cross-sectional profile in each stream reach separately; it is based on the one-dimensional mass and energy-balance equations solved over each stream reach (adapted from Gallice et al., 2015):

$$
\begin{aligned}
\frac{\partial A}{\partial t}+\frac{\partial Q}{\partial x} & =q_{\mathrm{subw}} \\
\frac{\partial\left(A T_{w}\right)}{\partial t}+\frac{\partial\left(Q T_{w}\right)}{\partial x} & =\frac{w \phi}{\rho_{\mathrm{w}} c_{\mathrm{p}, \mathrm{w}}}+q_{\mathrm{subw}} T_{\text {subw }} \\
& +Q \frac{g}{c_{\mathrm{p}, \mathrm{w}}} S_{0}
\end{aligned}
$$

where $t(\mathrm{~s})$ denotes time and $x(\mathrm{~m})$ the streamwise distance; $A\left(\mathrm{~m}^{2}\right), Q\left(\mathrm{~m}^{3} \mathrm{~s}^{-1}\right), T_{w}(\mathrm{~K})$ and $w(\mathrm{~m})$ stand for the cross-sectional area, discharge, temperature and width of the stream reach; $\phi\left(\mathrm{W} \mathrm{m}^{2}\right)$ corresponds to the sum of the net heat fluxes at the air-water and water-bed interfaces; $\rho_{\mathrm{w}}\left(\mathrm{kg} \mathrm{m}^{-3}\right)$ and $c_{\mathrm{p}, \mathrm{w}}\left(\mathrm{J} \mathrm{kg}^{-1} \mathrm{~K}^{-1}\right)$ denote the mass density and specific heat capacity of water; $q_{\text {subw }}\left(\mathrm{m}^{3} \mathrm{~s}^{-1} \mathrm{~m}^{-1}\right)$ is the lateral subsurface water inflow per unit streamwise distance; and $g\left(\mathrm{~m} \mathrm{~s}^{-2}\right)$ stands for the gravitational acceleration at the Earth's surface. Both $T_{\text {subw }}$, the temperature of subsurface water inflow, and $S_{0}$, the local bed slope, have been defined previously. Equations (9) and (10) are both written in conservative form. Assuming a smooth variation of $A, Q$ and $T_{w}$ along the stream reach, the partial derivatives on the lefthand side of Eq. (10) can be developed using the product rule. By inserting Eq. (9) and rearranging the terms, one obtains the following expression:

$$
\begin{aligned}
\frac{\partial T_{w}}{\partial x}+v \frac{\partial T_{w}}{\partial x}= & \frac{\phi}{\rho_{\mathrm{w}} c_{\mathrm{p}, \mathrm{w}} h}+\frac{q_{\text {subw }}}{h w}\left(T_{\text {subw }}-T_{w}\right) \\
& +\frac{g Q}{c_{\mathrm{p}, \mathrm{w}} h w} S_{0},
\end{aligned}
$$

where $v=Q / A\left(\mathrm{~m} \mathrm{~s}^{-1}\right)$ corresponds to the flow velocity and $h=A / w(\mathrm{~m})$ to the stream water depth.

In Eqs. (9)-(11), the values of $A, Q, v, h$ and $w$ are provided by the water routing module of StreamFlow (see Sect. 2.2.1), while $T_{\text {subw }}$ is obtained from the subsurface flux temperature module (see Sect. 2.1.2). The value of $q_{\text {subw }}$ is derived from the subsurface flux discharge $Q_{\text {subw }}$ (see Sect. 2.1.1) depending on the stream reach type. In lumped reaches, it is simply computed as $Q_{\text {subw }}$ divided by the reach length, whereas it is calculated in each discretized reach cell as the fraction of $Q_{\text {subw }}$ proportional to the cell-specific drainage area, divided by the cell length.

The net heat flux $\phi$ is computed as in Westhoff et al. (2007) with the following modifications:

1. Incoming short- and long-wave radiation are directly obtained from meteorological measurements. They are spatially interpolated by StreamFlow over the stream network using library MeteoIO (Bavay and Egger, 2014), taking topographic shading into account. Riparian forest shading is currently not represented in the model, hereby restricting the application of StreamFlow to high-altitude catchments. This limitation might be relaxed in the near future through the implementation of an appropriate shade model, taking, for instance, advantage of the improvements brought by Gouttevin et al. (2015) to the canopy module of Snowpack.

2. The heat flux at the water-bed interface $\phi_{\mathrm{b}}\left(\mathrm{W} \mathrm{m}^{-2}\right)$ is computed at any given point along the stream according to Haag and Luce (2008):

$\phi_{\mathrm{b}}=k_{\mathrm{bed}}\left(T_{\mathrm{bed}}-T_{w}\right)$,

where $k_{\text {bed }}\left(\mathrm{W} \mathrm{m}^{-2} \mathrm{~K}^{-1}\right)$ denotes the bed heat transfer coefficient, which corresponds to the bed heat conductivity multiplied by the distance over which the heat transfer occurs. The value of $k_{\text {bed }}$ can be freely specified by the user, but is fixed here to $52.0 \mathrm{~W} \mathrm{~m}^{-2} \mathrm{~K}^{-1}$ after Moore et al. (2005) and MacDonald et al. (2014). Stream bed temperature $T_{\text {bed }}(\mathrm{K})$ is assumed to be equal to soil temperature as modelled by Alpine3D at the point of interest, averaged over depth $z_{\mathrm{d}}$. This depth is the same one as used by the subsurface flux temperature module (see Sect. 2.1.2) and should be specified prior to running the Alpine3D simulation. It should be mentioned that hyporheic exchanges are neglected here, although Eq. (12) could theoretically account for them, provided that the values of $k_{\text {bed }}$ and $T_{\text {bed }}$ are adapted accordingly.

3. The latent heat flux $\phi_{1}\left(\mathrm{Wm}^{-2}\right)$ is approximated using a simplified Penman equation (e.g. Hannah et al., 2004; Haag and Luce, 2008; Magnusson et al., 2012):

$\phi_{\mathrm{l}}=-\frac{\rho_{\mathrm{a}} c_{\mathrm{p}, \mathrm{a}}}{\gamma}\left(a_{v w} v_{\text {wind }}+b_{v w}\right)\left(e_{\mathrm{s}}\left(T_{w}\right)-e\left(T_{\mathrm{a}}\right)\right)$,

where $T_{\mathrm{a}}(\mathrm{K}), \rho_{\mathrm{a}}\left(\mathrm{kg} \mathrm{m}^{-3}\right)$ and $c_{\mathrm{p}, \mathrm{a}}\left(\mathrm{J} \mathrm{kg}^{-1} \mathrm{~K}^{-1}\right)$ denote the temperature, mass density and specific heat capacity of air; $v_{\text {wind }}\left(\mathrm{m} \mathrm{s}^{-1}\right)$ the wind velocity; $\gamma\left(\mathrm{Pa} \mathrm{K}^{-1}\right)$ the psychrometric constant; $e_{\mathrm{S}}\left(T_{w}\right)(\mathrm{Pa})$ the saturated 
vapour pressure measured at stream temperature; and $e\left(T_{\mathrm{a}}\right)(\mathrm{Pa})$ the actual vapour pressure measured at air temperature. The values of parameters $a_{v w}$ (-) and $b_{v w}\left(\mathrm{~ms}^{-1}\right)$ are chosen after Webb and Zhang (1997), namely $a_{v w}=2.20 \times 10^{-3}$ and $b_{v w}=2.08 \times$ $10^{-3} \mathrm{~m} \mathrm{~s}^{-1}$, although they can be changed by the user.

4. The sensible heat flux $\phi_{\mathrm{h}}\left(\mathrm{W} \mathrm{m}^{-2}\right)$ is computed based on an approach similar to the one used in Comola et al. (2015), namely

$$
\phi_{\mathrm{h}}=-\rho_{\mathrm{a}} c_{\mathrm{p}, \mathrm{a}}\left(a_{v w} v_{\mathrm{wind}}+b_{v w}\right)\left(T_{w}-T_{\mathrm{a}}\right)
$$

This expression for $\phi_{\mathrm{h}}$ is preferred over the one used in Westhoff et al. (2007), since the latter contains a term $e_{\mathrm{S}}\left(T_{w}\right)-e\left(T_{\mathrm{a}}\right)$ in the denominator which we observed to be responsible for numerical instabilities when $T_{w}$ approaches $T_{\mathrm{a}}$ (not shown).

In the case of lumped stream reaches, StreamFlow uses the first-order upwind finite difference approximation of Eqs. (9)-(10) to estimate stream temperature $T_{\mathrm{w}, j}$ in each reach $j$ (see, e.g. Westhoff et al., 2007):

$$
\begin{aligned}
A_{j} \frac{\mathrm{d} T_{\mathrm{w}, j}}{\mathrm{~d} t}= & \frac{Q_{\mathrm{in}, j}}{L_{j}}\left(T_{\mathrm{in}, j}-T_{\mathrm{w}, j}\right)+q_{\mathrm{subw}, j}\left(T_{\mathrm{subw}, j}-T_{w}\right) \\
& +\frac{w_{j} \phi_{j}}{\rho_{\mathrm{w}} c_{\mathrm{p}, \mathrm{w}}}+L_{j} Q_{j} \frac{g}{c_{\mathrm{p}, \mathrm{w}}} \overline{S_{0}}
\end{aligned}
$$

where $A_{j}\left(\mathrm{~m}^{2}\right), Q_{j}\left(\mathrm{~m}^{3} \mathrm{~s}^{-1}\right), \overline{S_{0}}(-), L_{j}(\mathrm{~m})$ and $w_{j}(\mathrm{~m})$ denote the cross-sectional area, outlet discharge, mean bed slope, length and width of reach $j$, and $\phi_{j}\left(\mathrm{~W} \mathrm{~m}^{-2}\right)$ corresponds to the net heat flux into reach $j . Q_{\text {in, } j}$ and $T_{\text {in, } j}$ stand for the discharge and temperature of water draining into the reach inlet. $Q_{\text {in }, j}$ is simply computed as the sum of the outlet discharges of the upstream reaches, whereas $T_{\text {in, } j}$ is approximated as the discharge-weighted mean of the outlet temperatures of the upstream reaches. $T_{\text {subw, } j}$ and $q_{\text {subw, } j}$ denote the temperature and discharge per unit streamwise distance of the subsurface water inflow into reach $j$. Equation (15) is discretized in time using an implicit Euler scheme, whose solution is obtained thanks to the simplified Brent root-finding method proposed by Stage (2013).

In discretized stream reaches, Eq. (11) is solved using a splitting scheme (e.g. LeVeque, 2002). The idea is to decompose the equation into two simpler ones, where the solution of the first equation serves as the initial condition for the second one. Similarly to Loinaz et al. (2013), we chose here to separate heat advection from the accounting of the heat sources, since standard approaches are available for the numerical resolution of advection in the absence of sources. The resulting splitting scheme is the following (adapted from
Loinaz et al., 2013):

$$
\begin{aligned}
\frac{\partial T_{w}}{\partial t}+v \frac{\partial T_{w}}{\partial x}= & 0, \\
\frac{\mathrm{d} T_{w}}{\mathrm{~d} t}= & \frac{\phi}{\rho_{\mathrm{w}} c_{\mathrm{p}, \mathrm{w}} h}+\frac{q_{\mathrm{subw}}}{h w}\left(T_{\mathrm{subw}}-T_{w}\right) \\
& +\frac{g Q}{c_{\mathrm{p}, \mathrm{w}} h w} S_{0} .
\end{aligned}
$$

Equation (16) is discretized over each stream reach using an explicit upwind finite volume scheme with second-order precision in space and first-order precision in time (Berger et al., 2005):

$T_{\mathrm{w}, i}^{n+1}=T_{\mathrm{w}, i}^{n}-\frac{v_{i}^{n} \Delta t}{l_{i}}\left(T_{\mathrm{w}, i+1 / 2}^{L}-T_{\mathrm{w}, i-1 / 2}^{L}\right)$.

In the above equation, $T_{\mathrm{w}, i}^{n}(\mathrm{~K})$ and $v_{i}^{n}\left(\mathrm{~m} \mathrm{~s}^{-1}\right)$ denote the stream temperature and flow velocity in reach cell $i$ at time $t_{n}, \Delta t$ corresponds to the time step and $l_{i}$ is the length of cell $i$. $T_{\mathrm{w}, i+1 / 2}^{L}(\mathrm{~K})$ refers to the so-called "left state" at the right boundary of cell $i$, which is computed as

$T_{\mathrm{w}, i+1 / 2}^{L}=T_{\mathrm{w}, i}^{n}+\frac{1}{2} \psi_{i}\left(T_{\mathrm{w}, i}^{n}-T_{\mathrm{w}, i-1}^{n}\right)$

where the factor $\psi_{i}(-)$, known as a "slope limiter", is introduced so as to limit numerical dispersion. Many slope limiters have been derived for regular space discretizations (LeVeque, 2002), but very few are available for irregular meshes (Berger et al., 2005; Zeng, 2013). StreamFlow implements the slope limiter developed by Zeng (2013),

$\psi_{i}=\frac{B\left(r+r^{k}\right)}{1+A r^{k}}$,

with

$r=\frac{T_{\mathrm{w}, i+1}-T_{\mathrm{w}, i}}{T_{\mathrm{w}, i}-T_{\mathrm{w}, i-1}}$,

$A=\frac{l_{i-1}+l_{i}}{l_{i}+l_{i+1}}$

$B=\frac{2 l_{i}}{l_{i}+l_{i+1}}$,

$k=\left\lceil\frac{B}{2 \min (1, A)-B}\right\rceil$.

The solution to Eq. (18) is used as initial condition for Eq. (17), which is discretized in time according to an implicit Euler scheme and solved using the root-finding method developed by Stage (2013). A validation of the splitting scheme can be found in Appendix B, where it is compared with analytical solutions to the heat-balance equation in two simple test cases. 


\section{Model implementation}

In order to allow for the calibration of its parameters, StreamFlow was developed as a stand-alone program rather than being seamlessly integrated into Alpine3D. This permits a higher flexibility, since Alpine3D - whose typical computation time is of the order of $24 \mathrm{~h}$ when simulating a 1-year period on a standard personal computer - does hereby not need to be newly run each time a new parameter set is tested in StreamFlow. Regarding the computation time of StreamFlow itself, we observed the simulation duration to be highly dependent on the methods used to compute the transport of water and heat along the stream network. In general, the lumped approaches are associated with much-reduced computation times as compared to the discretized methods, and the Muskingum-Cunge water routing technique is slower than its instantaneous advection counterpart. As an indication, the stream temperature simulations reported in Sect. 4, which were run on a personal computer with $2 \mathrm{~GB}$ of RAM and an Intel ${ }^{\circledR}$ Core $^{\mathrm{TM}}$ i7 processor, took between a few seconds (with the lumped instantaneous routing approach) and more than $24 \mathrm{~h}$ (with the discretized Muskingum-Cunge approach) to complete.

For the sake of consistency, StreamFlow is, similarly to Alpine3D, implemented in $\mathrm{C}++$ and compiled using CMake. The choice was made to use version $\mathrm{C}++11$ of the $\mathrm{C}++$ language, since it offers new practical features such as anonymous functions or the "range-based" FOR loops as compared to the $\mathrm{C}++99$ standard (Lippman et al., 2012) - regardless of the fact that $\mathrm{C}++11$ is meant to supersede $\mathrm{C}++99$ in the long term. The same coding strategy as detailed in Bavay and Egger (2014) is used here, namely the following:

- Advantage is taken of the object-oriented nature of C++ to clearly structure the code and make it as modular as possible, so as to facilitate understandability and ease future developments.

- The dependence towards third-party software is avoided as much as possible in order to limit installation issues. The only external utility required by StreamFlow is the library MeteoIO (Bavay and Egger, 2014), which is used to read input files and interpolate meteorological data in space and time.

- Significant effort is put into documenting the code, both for end users and future developers. Online documentation provides indications regarding the installation procedure and the steps to follow in order to launch a simulation (see http://models.slf.ch/p/streamflow/doc/). In addition, technical documentation is directly integrated into the source code using the doxygen tool (van Heesch, 2008).

- Particular attention is paid to keeping the coding style consistent. This task is facilitated by the small size of the development team - mostly one person - and the young age of the project - the creation of StreamFlow dates from 2015. The coding style is essentially the same as in MeteoIO, with additional conventions regarding the naming of class attributes (see http:// models.slf.ch/p/streamflow/page/CodingStyle/).

- When compiling the code, all possible gcc warnings are activated and requested to be passed successfully. The code currently compiles on Windows, Linux and OS X.

- The program is designed so as to be as flexible as possible. In particular, its behaviour can be adapted without recompiling the code by modifying the configuration file, which regroups all adjustable parameters. Additionally, the use of library MeteoIO for preprocessing allows input data to be provided in a large variety of formats.

- Daily automated tests were set into place using CTest. This ensures that potential errors introduced by code modifications are rapidly identified and corrected, therefore increasing code stability.

The following sections provide some details about the code implementation and the program work flow.

\subsection{Program main architecture}

The architecture of the program core is depicted as a Unified Modelling Language diagram (UML diagram; see, e.g. Booch et al., 2005) in Fig. 3. The code is essentially structured around a main class, "HydrologicalModel", which regroups two different objects:

- The first object is an instance of class "Watershed", in charge of computing the transport of water and heat within the hillslopes. This class is itself a container storing a collection of "Subwatershed" objects, each one of them representing one of the subwatersheds delineated by TauDEM (see Sect. 2). The computation of discharge and temperature at the outlet of each subwatershed is not performed in class Subwatershed directly, but in its subclasses instead. The idea behind this approach is to implement each alternative method for the computation of the subwatershed outflow discharge and/or temperature in a different subclass of class Subwatershed. Thus, since no spatially discretized techniques have been implemented in the code to date, class Subwatershed only has one subclass, LumpedSubwatershedInterface, which defines the interface to be implemented by lumped subwatersheds - i.e. subwatersheds being treated as single points (see Sect. 2.1.1). Future code developments could include the definition of a second interface inherited from Subwatershed, representing the subwatersheds as spatially distributed entities. 


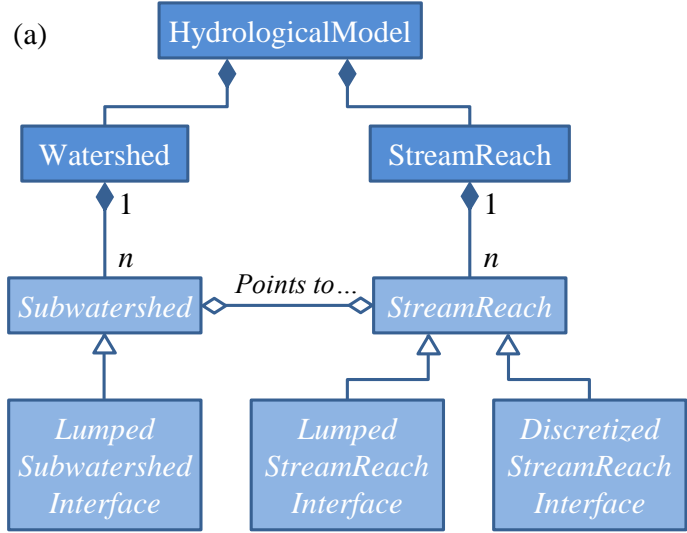

(b)

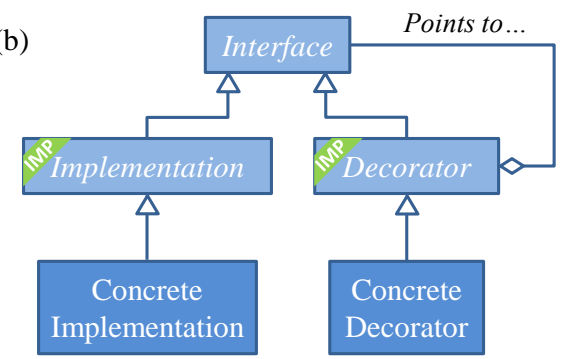

Abstract class
Concrete class

Figure 3. Structure of StreamFlow's source code. (a) Simplified diagram of StreamFlow's high-level classes; (b) diagram of the Decorator pattern used to implement abstract classes "LumpedSubwatershedInterface", "LumpedStreamReachInterface" and "DiscretizedStreamReachInterface".

- The second object is an instance of class "StreamNetwork", responsible for advecting water and heat along the stream network. This class contains a collection of "StreamReach" objects, which are intended to represent the actual stream reaches identified by TauDEM (see Sect. 2). Each StreamReach object holds a pointer to the Subwatershed instance it is associated with - and vice versa. Similarly to class Subwatershed, class StreamReach does not perform the discharge and temperature computations itself, but delegates it to its subclasses instead. As such, two classes inherit from StreamReach: LumpedStreamReachInterface representing lumped stream reaches, and DiscretizedStreamReachInterface symbolizing discretized stream reaches.

As indicated in Fig. 3, the low-level classes described above - namely classes Subwatershed and StreamReach, along with their respective direct subclasses - are abstract. An abstract class in $\mathrm{C}++$ is roughly equivalent to an interface in Java, i.e. it defines the set of methods which need to be implemented by its subclasses. In the present case, the use of abstract classes enabled us to implement the various water and heat transport methods in separated subclasses. Indeed, as mentioned above, we sought at creating one subclass for each water or heat transport technique described in Sect. 2. For instance, some of the subclasses of class LumpedStreamReachInterface concentrate on the advection of water in the stream reach, while others compute the advection of heat only. Similarly, the subclasses of class LumpedSubwatershedInterface are split between those focusing on subsurface discharge computation and those dealing with the modelling of the subsurface flux temperature. This approach not only helps with clarifying the code structure but also allows for the combination of every discharge computation technique with each temperature calculation method.

The association of a particular discharge computation technique with a given temperature modelling approach is performed in the code using the Decorator pattern. This standard design pattern, illustrated in Fig. $3 b$, enables the dynamic extension of the functionality of a class (Gamma et al., 1994). In the figure, the parent class "Interface" stands for any of the abstract classes (LumpedSubwatershedInterface, LumpedStreamReachInterface or DiscretizedStreamReachInterface) described above (see Fig. 3a): the general structure described hereafter is the same in all three cases, expect that the class names differ. Class Interface is subdivided into two classes, named "Implementation" and "Decorator" in Fig. 3b. Class Implementation defines the interface to be implemented by all the subclasses computing discharge, while class Decorator corresponds to the parent of all classes focusing on temperature calculation. This structure allows for a clearer separation between the subclasses concerned with discharge computation from those modelling temperature. Inheriting from class Implementation, class "ConcreteImplementation" stands for any non-abstract class modelling discharge. Similarly, class "ConcreteDecorator" - which inherits from class Decorator - corresponds to any concrete subclass modelling heat transport. The characteristic of the Decorator pattern resides in the fact that each Decorator object holds a pointer to an Interface instance. In this sense, class Decorator acts as a wrapper around a pointed (or, in other words, decorated) object of type Interface. In practice, the pointed objects are always of derived type ConcreteImplementation. Each call to a member function of the Decorator instance is typically forwarded to the decorated object, with additional operations occurring before and/or after the forwarded function call, hereby extending the functionality of the decorated ConcreteImplementation object. For example, each one of the three approaches described in Sect. 2.1.2 for computing the temperature of the subsurface water flux is implemented in StreamFlow as a separate subclass of class Decorator. These subclasses can be used to wrap the version of class ConcreteImplementation corresponding to the linear reservoir approach detailed in Sect. 2.1.1, therefore providing it with the ability to compute the subsurface flux tem- 
perature. It should be mentioned that classes Implementation and Decorator have been designed in StreamFlow so as to be easily subclassed by a casual developer, therefore facilitating the implementation of future discharge or temperature computation methods.

\subsection{Input reading}

For StreamFlow to run properly, Alpine3D has to be configured so as to output the grids of the water percolation rate at the bottom of the soil columns. In case stream temperature is to be computed, StreamFlow additionally expects grids of soil temperature from Alpine3D (see Sect. 2.1.2), on top of the same meteorological measurements as those required by Alpine3D as input. These measurements will be interpolated by MeteoIO over the stream reaches, taking topographic shading into account in the case of incoming shortwave radiation.

Similarly to MeteoIO, StreamFlow processes its input files in a centralized manner, hereby facilitating the understanding and reuse of the code by casual developers. All required files are parsed by a single class, "InputReader", which supports various input formats thanks to the integrated use of MeteoIO utilities (see Bavay and Egger, 2014). It delegates the actual parsing of the input files to low-end classes, devised to be easily modified or enriched by end users.

\subsection{Output writing}

As a result of its semi-distributed nature, StreamFlow is able to output the discharge and temperature of the subsurface water flux produced by each subwatershed, as well as the water depth, discharge and temperature in each stream reach. Output files are currently produced in the SMET format (see https://models.slf.ch/docserver/meteoio/SMET_ specifications.pdf), for which various utilities - such as parsing and visualizing functions in Matlab and Python - are available in MeteoIO. The possibility is offered to the user to generate output files only for certain subwatersheds and/or stream reaches.

As for the parsing of the input files, the writing of the output data is handled by a high-level class, "OutputWriter", which delegates the actual generation of the output files to low-level classes. As mentioned in the previous section, this architecture both facilitates future developments and eases the understanding of the global code structure.

\subsection{Calibration module}

StreamFlow comes with an optimization module used to calibrate the model parameters. It aims to identify the parameter set minimizing the so-called "objective function". The latter can be freely specified by the user based on the following standard error measures:

- the root mean square error (RMSE);
- the Nash-Sutcliffe efficiency (NSE; Nash and Sutcliffe, 1970), also known as the coefficient of determination $R^{2}$

- the mean absolute error (MAE), corresponding to the average over all time steps of the model error absolute values; and

- the bias, defined as the mean value of the model errors over all time steps.

Each one of the above four measures can be evaluated either for water depth, discharge or temperature, bringing a total of 12 different error measures at disposal. StreamFlow also supports the case where measurement data are available at more than one point along the stream network. The objective function can be defined as any weighted sum of some (or all) of the available error measures, hereby making the model calibration entirely flexible. Monte Carlo simulations are currently used for calibrating the model, but other wellknown optimization algorithms, such as DREAM (Vrugt and Ter Braak, 2011) or GLUE (Beven and Binley, 1992), could be easily integrated into the code.

For the sake of modularity and flexibility, the list of model parameters is not managed centrally in the source code. Instead, each parametrizable class is responsible for defining its own associated parameters. This operation is performed through inheritance of a dedicated abstract class, "ParametrizableObject", which essentially possesses two member functions: "getParameters" and "setParameters" for obtaining and modifying the class parameters, respectively. The calibration module can then reconstruct the complete list of model parameters by simply calling method getParameters on each object inheriting from ParametrizableObject. Based on this list, it can compute new parameter values to be tested, which are transferred back to the individual objects through a call to their method setParameters.

In addition to its name, value and units, each model parameter in StreamFlow is associated with a range of physically acceptable values and a flag specifying whether it should be calibrated or not. The physically acceptable range is used by the calibration module to restrict the search domain for the best parameter value. The properties of each parameter can be freely set by the user in the program configuration file. In particular, the calibration flag can be individually set to true or false for every parameter, hereby making it possible to calibrate only a given subset of parameters.

\section{Case study}

In view of assessing its accuracy and demonstrating some of its capabilities, StreamFlow is tested over a high-altitude catchment in Switzerland. Section 4.1 presents the test catchment and the measurement data used to validate the model. The model setup is described in Sect. 4.2 and the simulation results are detailed in Sect. 4.3. 


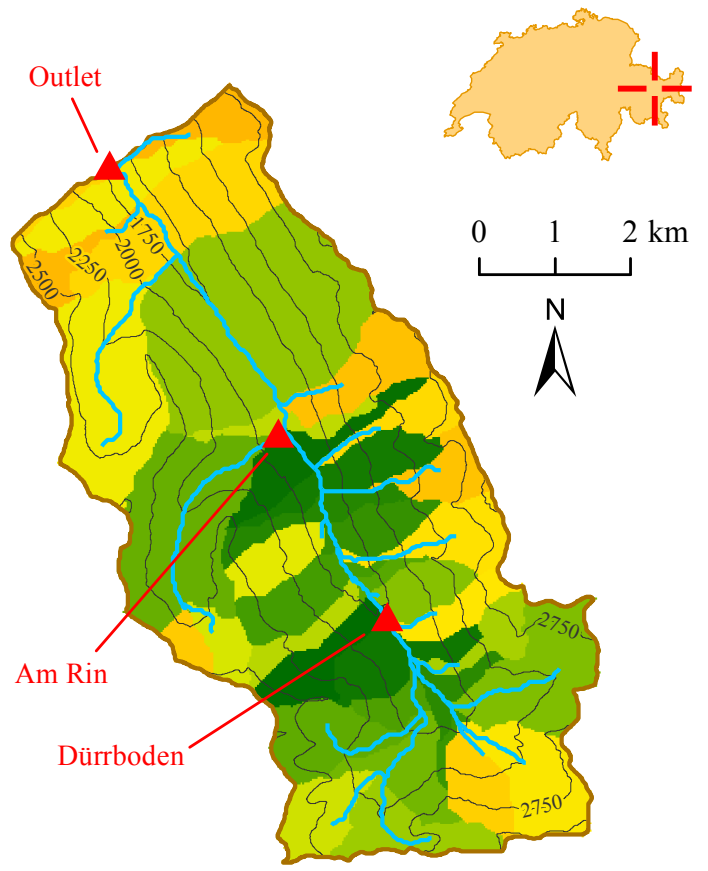

Figure 4. Map of the Dischma catchment displaying the subwatersheds (coloured areas) and stream network (light blue line) derived from the DEM using TauDEM. The locations of the stream gauges are indicated as red triangles.

\subsection{Study site and measurement data}

StreamFlow is tested over the Dischma catchment, located in the eastern Swiss Alps (see insert in Fig. 4). The gauging station operated by the Swiss Federal Office for the Environment (FOEN) at the location named Davos Kriegesmatte - referred to as "Outlet" in Fig. 4 - is chosen as the catchment outlet. At this point, the watershed has an area of $43.3 \mathrm{~km}^{2}$ and is mostly covered with pasture (36\%), rock outcrops ( $24 \%$ ) and bare soil (16\%), with only $2 \%$ of glacier cover (Schaefli et al., 2014). Very little riparian vegetation is present along the stream, which ensures that the current absence of riparian shade model in StreamFlow does not have a large influence on the quality of the stream temperature simulation. The watershed elevation ranges from about $1700 \mathrm{~m}$ to more than $3100 \mathrm{~m}$ above sea level. Its hydrological regime was classified as glacio-nival by Aschwanden and Weingartner (1985), i.e. the stream discharge is low in winter and peaks in June-July due to snow and ice melt, therefore corresponding to a typical watershed over which StreamFlow is meant to be used. More information on the Dischma catchment can be found in, e.g. Zappa et al. (2003) and Schaefli et al. (2014).

Water depth, discharge and temperature are continuously monitored by the FOEN at the catchment outlet. In complement to the quality control performed by the FOEN, hourly mean data are also corrected here using the procedure de- scribed in Gallice et al. (2015), namely a combination of visual inspection and automatized outlier identification. In addition to the FOEN station, two temporary gauging stations were installed starting on 16 January 2015 at the locations named Am Rin and Dürrboden, indicated as red triangles in Fig. 4. The gauging station at Am Rin was positioned in a small stream coming from a side valley, just above its confluence with the main stream, and remained in place until 17 July 2015. The station at Dürrboden was deployed in the upper part of the main stream, just below the confluence with the rivulet coming from the glacier. It was dismantled on 25 September 2015. Both stations continuously measured water depth and stream temperature with a sampling rate of $1 \mathrm{~h}$. Discharge was manually estimated using the salt dilution technique on a few days during winter and spring, which enabled the derivation of a rating curve to convert the continuous water depth measurements into discharge values (e.g. Weijs et al., 2013). The data from the gauging stations at Am Rin and Dürrboden are corrected using the same protocol as the data provided by the FOEN.

The meteorological data used to run the Alpine3D simulation and compute the stream temperature in StreamFlow are obtained from two different sources:

a. One of the sources is the Swiss Federal Office of Meteorology and Climatology, MeteoSwiss, which operates a country-wide network of automatic weather stations. Two of these are in the vicinity of the Dischma catchment: the Davos and Weissfluhjoch stations, whose respective locations are about 5 and $8.5 \mathrm{~km}$ on the northwest of the catchment outlet. They are both equipped with heated rain gauges, the one at Davos being unshielded and the one at Weissfluhjoch shielded. These stations provide measurements of air temperature, relative humidity, incoming long- and short-wave radiation, precipitation, wind direction and snow height every hour.

b. The other source is the Intercantonal Measurement and Information System (IMIS), a network of automated weather stations mostly used for avalanche forecasting in Switzerland (Lehning et al., 1999). Four of these stations are used in the present study, whose distances to the catchment outlet are $0.9,4.7,5.9$ and $9.5 \mathrm{~km}$. They provide hourly measurements of air temperature, relative humidity, outgoing short-wave radiation, wind speed and snow depth.

All meteorological time series are visually inspected to detect sensor failure. Data flagged as erroneous are removed from the time series.

\subsection{Model setup}

As mentioned previously, StreamFlow requires Alpine3D to be executed first. In the present case, Alpine3D is run over a 
grid with $100 \mathrm{~m}$ resolution and with an internal time step of $15 \mathrm{~min}$. The simulated time period extends over 3 hydrological years, namely from 1 October 2012 to 1 October 2015. All meteorological input data are spatially interpolated using the inverse-distance weighting approach with lapse rate, except for solar radiation and precipitation. Solar radiation is computed based on the measurements at the Weissfluhjoch station alone, taking atmospheric attenuation into account for each grid cell separately. Precipitation is interpolated using the data measured at the Davos station only. It is corrected for undercatch using the approach advocated by the World Meteorological Organization (WMO) for Hellmann gauges (Goodison et al., 1998), before being distributed over each grid cell based on a lapse rate proportional to the measured precipitation intensity at Davos. Another procedure using the data from the Weissfluhjoch station in addition to the one from Davos was also tested for interpolating precipitation. However, it was rejected since it largely overestimated the total amount of precipitation falling over the catchment, due to the existence of a strong north-south precipitation gradient in the area, making the measurements at the Weissfluhjoch station - located further north - less representative of the situation in the Dischma catchment than those at the Davos station - located closer to the catchment (Voegeli et al., 2016).

As an additional preliminary step to the StreamFlow simulation, the stream network and its corresponding set of subwatersheds are, as described in Sect. 2, extracted from a $25 \mathrm{~m}$ resolution DEM provided by the Swiss Federal Office of Topography, SwissTopo (see https://shop.swisstopo.admin. ch/en/products/height_models/dhm25). Application of the automatic Peuker-Douglas extraction method provided by TauDEM (see http://hydrology.usu.edu/taudem/taudem5/ help53/PeukerDouglas.html) results in a subdivision of the catchment into 39 subwatersheds, ranging in size from 0.2 ha to $6.4 \mathrm{~km}^{2}$ (see Fig. 4). It should be mentioned that the difference in resolution between the DEM provided as input to Alpine3D $(100 \times 100 \mathrm{~m})$ and the one used to extract the stream network $(25 \times 25 \mathrm{~m})$ is seamlessly handled by StreamFlow. This allows, as in the present case, for Alpine3D to be run over a coarser grid than StreamFlow, hereby saving computational power and resources.

StreamFlow is configured so as to compute the width $w$ of each stream reach as $w=a_{w} A_{\text {reach,tot }}+b_{w}$, where $A_{\text {reach,tot }}\left(\mathrm{m}^{2}\right)$ denotes the total area drained by the reach - including its upstream reaches. Parameters $a_{w}\left(\mathrm{~m}^{-1}\right)$ and $b_{w}(\mathrm{~m})$ are determined approximately based on the width of the main stream estimated at sample locations using aerial photographs of the Dischma catchment. In addition, the values of parameters $\alpha_{h}$ and $\beta_{h}$, which are required by the model to estimate water depth when simulating discharge based on the instantaneous advection technique (see Sect. 2.2.1), are derived from the discharge gauging curve provided by the FOEN at the catchment outlet. All model parameters used for the StreamFlow simulations presented in the next section are summarized in Table 2, along with their respective calibration ranges when appropriate. For the purpose of reducing the impact of the initial conditions on the modelled stream variables, a warm-up period of 1 year is considered. In other words, the model is run over a random year before each simulation, and its state at the end of the warm-up period is used as an initial condition for the actual simulation. This approach is observed to improve the quality of the simulation - notably of modelled discharge - by letting enough time for the amount of water stored in the linear reservoirs representing the subwatersheds to adapt to the inflow conditions (not shown). The model is calibrated over hydrological year 2013 using Monte Carlo simulations, and validated over hydrological years 2014 and 2015. Calibration is performed in two steps:

1. All parameters associated with water routing, whether within the hillslopes or along the stream network, are calibrated by maximizing the Nash-Sutcliffe efficiency of simulated discharge at the catchment outlet. Only the parameters associated with the modelling of the subsurface flux discharge are actually calibrated in this step (namely $R_{\max }, \bar{\tau}_{\text {res,u }}$ and $\bar{\tau}_{\text {res, } 1 \text { ), since the only parame- }}$ ter related to water routing within the stream channels (i.e. Manning's coefficient) is fixed to some predefined value (see Sect. 4.3 and Table 2).

2. The parameters calibrated in step 1 are kept fixed to their respective best values, while the parameters related to stream temperature modelling are calibrated by maximizing the NSE of simulated temperature at the catchment outlet. This step is repeated for each method used to compute the temperature of the subsurface water flux (see Sect. 2.1.2). The parameters associated with the water heat balance in the stream network are fixed to specific values based on physical considerations (see Table 2).

In order to better assess the accuracy of StreamFlow, the approach advocated by Schaefli and Gupta (2007) is followed here. The error measures associated with StreamFlow are compared to those of a simplistic benchmark model, so as to verify whether StreamFlow allows for more robust predictions than those that could be made based on a basic procedure. Two benchmark models are actually considered here, one for discharge and one for temperature. Both are constructed by averaging, for each hour of each day of the year, the values of discharge and temperature measured at the catchment outlet on those particular hours and days between 2005 and 2014. For example, the output of the discharge benchmark model on 1 January at 13:00 UTC is the same for all years and corresponds to the average of the 10 discharge values measured at the catchment outlet on 1 January at 13:00 UTC from 2005 to 2014. 
Table 2. Parameters used by StreamFlow to simulate water depth, discharge and temperature using various approaches. The parameters are described in more detail in the main text (Sect. 2 and Appendix A). First column of the table mentions the part of the model in which the parameter is used. The absence of a calibration range (marked as n/a) indicates a fixed parameter.

\begin{tabular}{|c|c|c|c|c|c|c|}
\hline Model part & Parameter & Units & Defined in & $\begin{array}{l}\text { Calibrated or } \\
\text { chosen value }\end{array}$ & $\begin{array}{l}\text { Calibration } \\
\text { range }\end{array}$ & $\begin{array}{l}\text { Rationale for the chosen } \\
\text { value or calibration range }\end{array}$ \\
\hline \multirow{3}{*}{$\begin{array}{l}\text { Subwatershed } \\
\text { outflow discharge } \\
\text { (Sect. } 2.1 .1 \text { ) }\end{array}$} & $R_{\max }$ & $\left(\mathrm{mm} \mathrm{day}{ }^{-1}\right)$ & main text & 6.93 & {$[0,50]$} & Comola et al. (2015) \\
\hline & $\bar{\tau}_{\text {res,u }}$ & (day) & Eq. (A5) & 22.5 & {$[0,60]$} & Comola et al. (2015) \\
\hline & $\bar{\tau}_{\text {res }, 1}$ & (day) & Eq. (A6) & 567.1 & {$[0,600]$} & Comola et al. (2015) \\
\hline \multirow{4}{*}{$\begin{array}{l}\text { Subwatershed } \\
\text { outflow temperature } \\
\text { (Sect. 2.1.2) }\end{array}$} & $k_{\text {soil }}$ & (day) & Eqs. (A7)-(A8) & 49.6 & {$[0,50]$} & Comola et al. (2015) \\
\hline & $\tau_{\mathrm{HSPF}}$ & (day) & Eq. (1) & 58.2 & {$[0.1,100]$} & \\
\hline & $D_{\mathrm{HSPF}}$ & $\left({ }^{\circ} \mathrm{C}\right)$ & Eq. (1) & 0.99 & {$[-3,1]$} & \\
\hline & $z_{\mathrm{d}}$ & (m) & main text & 2.40 & $\mathrm{n} / \mathrm{a}$ & \\
\hline \multirow{5}{*}{$\begin{array}{l}\text { Channel } \\
\text { water discharge } \\
\text { (Sect. 2.2.1) }\end{array}$} & $a_{w}$ & $\left(m^{-1}\right)$ & main text & $1.52 \times 10^{-7}$ & $\mathrm{n} / \mathrm{a}$ & aerial photographs \\
\hline & $b_{w}$ & & main text & 0.39 & $\mathrm{n} / \mathrm{a}$ & aerial photographs \\
\hline & $\alpha_{h}$ & $\left(\mathrm{~m}^{1-3 \beta_{h}{ }_{\mathrm{S}} \beta_{h}}\right)$ & main text & 0.57 & $\mathrm{n} / \mathrm{a}$ & $\begin{array}{l}\text { discharge gauging curve } \\
\text { at watershed outlet }\end{array}$ \\
\hline & $\beta_{h}$ & $(-)$ & main text & 0.32 & $\mathrm{n} / \mathrm{a}$ & same as for $\alpha_{h}$ \\
\hline & $n_{\mathrm{m}}$ & $(-)$ & Eqs. (5) and (7) & $0.04,0.07,0.10$ & $\mathrm{n} / \mathrm{a}$ & Phillips and Tadayon (2006) \\
\hline \multirow{3}{*}{$\begin{array}{l}\text { Channel } \\
\text { water temperature } \\
\text { (Sect. 2.2.2) }\end{array}$} & $a_{v w}$ & $(-)$ & Eq. (13) & $2.20 \times 10^{-3}$ & $\mathrm{n} / \mathrm{a}$ & Webb and Zhang (1997) \\
\hline & $b_{v w}$ & $\left(\mathrm{~ms}^{-1}\right)$ & Eq. (13) & $2.08 \times 10^{-3}$ & $\mathrm{n} / \mathrm{a}$ & Webb and Zhang (1997) \\
\hline & $k_{\text {bed }}$ & $\left(\mathrm{W} \mathrm{m} \mathrm{m}^{-2} \mathrm{~K}^{-1}\right)$ & Eq. (12) & 52.0 & $\mathrm{n} / \mathrm{a}$ & $\begin{array}{l}\text { Moore et al. (2005) and } \\
\text { MacDonald et al. (2014) }\end{array}$ \\
\hline
\end{tabular}

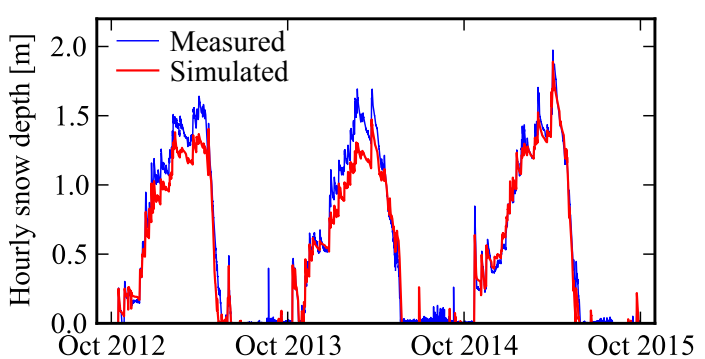

Figure 5. Comparison between the measured (blue line) and simulated (red line) time evolution of snow depth at the Stillberg meteorological station. The simulated curve corresponds to the mean snow depth as computed by Alpine3D over the $100 \times 100 \mathrm{~m}$ grid cell containing the Stillberg station.

\subsection{Model evaluation}

\subsubsection{Results of the Alpine3D simulation}

The Alpine3D simulation is observed to rather accurately capture the time evolution of the snow pack. As an example, Fig. 5 depicts the simulated snow depth in comparison with the measured one at the Stillberg meteorological station, which is located at an altitude of $2085 \mathrm{~m}$ above sea level on the western slope of the catchment. It can be noticed that the onset of snow accumulation and the timing of the melting period are satisfyingly reproduced, in addition to the fact that the snow depth appears to be overall well simulated. A more
Table 3. Comparison of the total volume of water ( $\left.V_{\text {in,simu }}\right)$ simulated by Alpine3D to percolate at the bottom of the watershed soil columns over each year, and the measured total volume of water ( $\left.V_{\text {out,meas }}\right)$ flowing out of the catchment each year via the river.

\begin{tabular}{lrrr}
\hline $\begin{array}{l}\text { Hydrological } \\
\text { year }\end{array}$ & $\begin{array}{r}V_{\text {in,simu }}\left(\mathrm{m}^{3}\right) \\
2013\end{array}$ & $\begin{array}{r}V_{\text {out,meas }} \\
\left(\mathrm{m}^{3}\right)\end{array}$ & $\begin{array}{r}\text { Relative } \\
\text { difference }(\%)\end{array}$ \\
\hline 2014 & $5.28 \times 10^{7}$ & $5.64 \times 10^{7}$ & -6.3 \\
2015 & $5.88 \times 10^{7}$ & $5.57 \times 10^{7}$ & 5.7 \\
\hline
\end{tabular}

quantitative assessment of the accuracy of the Alpine3D simulation is obtained by considering the global volume of water transiting through the watershed each year. Thus, the measured cumulated volume of water ( $\left.V_{\text {out,meas }}\right)$ flowing through the catchment outlet each year is compared to the simulated cumulated volume of water $\left(V_{\text {in,simu }}\right)$ percolating at the bottom of all the soil columns belonging to the watershed over the same year. As can be observed in Table 3, the relative difference between $V_{\text {out,meas }}$ and $V_{\text {out,simu }}$ remains within the range $\pm 8 \%$ for all 3 hydrological years.

\subsubsection{StreamFlow simulations of discharge and water depth}

As mentioned in the previous section, StreamFlow parameters related to discharge computation are calibrated against measured discharge at the catchment outlet. To this end, 

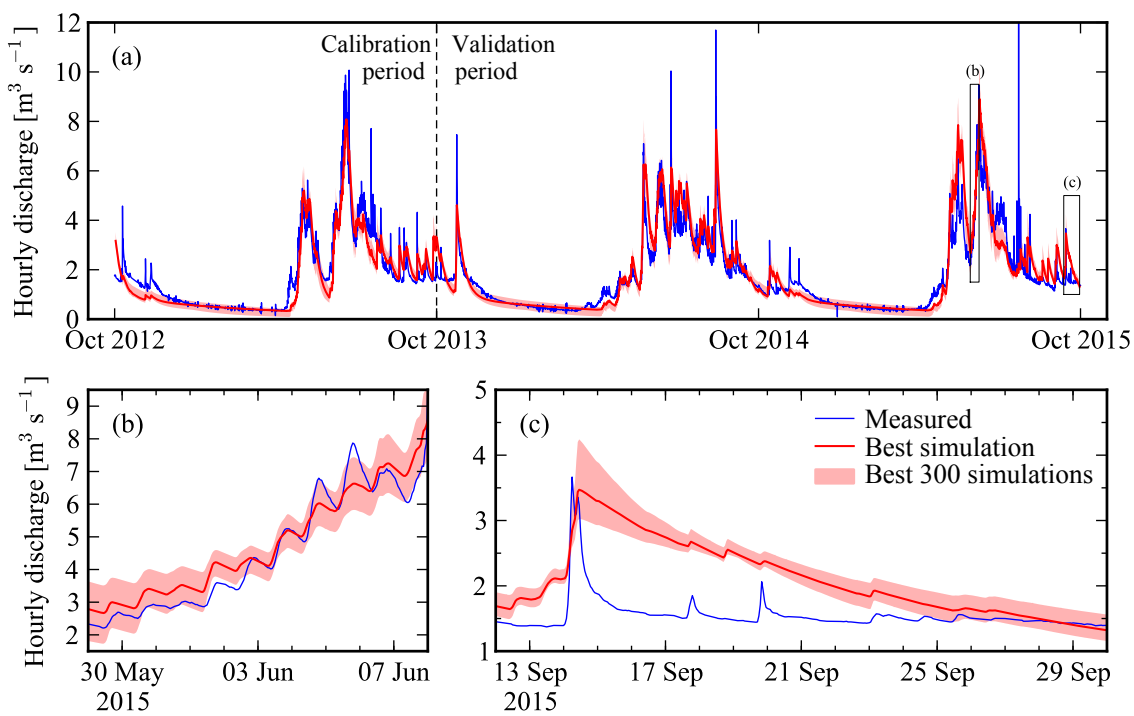

Figure 6. Comparison between the measured (blue line) and simulated (red line) time evolution of hourly mean discharge at the watershed outlet. Panel (a) pictures the entire simulated period, and panels (b) and (c) correspond to zooms on two selected time periods (their extents are indicated as black rectangles in panel a). The simulated curve was obtained with StreamFlow configured so as to advect water in the stream channels using the instantaneous routing approach. The uncertainty range corresponds to the 300 best runs of the model out of the 10000 Monte Carlo simulations.

10000 Monte Carlo simulations are run, with StreamFlow configured so as to use a time step of $1 \mathrm{~h}$ and advect water in the stream channels based on the instantaneous routing scheme (see Sect. 2.2.1). Figure 6 presents a comparison of the simulated and measured hourly mean discharges over the 3 considered hydrological years. The uncertainty range of the simulated curve is defined by all parameter sets associated with a NSE larger than 0.85 during the calibration period, which amounts to a total of 300 curves. As observed in panel a, the simulation corresponding to the highest NSE value matches globally well with the observations, except for a few discharge peaks which are not well captured in 2013 and 2015. The simulation uncertainty range appears to be relatively narrow on an annual scale. When looking at a finer scale, it can be observed that the daily fluctuations of discharge are relatively well captured by the model as, for example, shown in panel $b$ for the period 29 May to 8 June 2015 . On the other hand, the absence of a fast runoff component in StreamFlow prevents the model to correctly capture shortlived discharge peaks. As displayed in panel c, the modelled recession in these cases is much too slow compared to the observed one. This model limitation could be fixed by implementing a new method for transferring water across the subwatersheds, based on a more physically based approach than the linear reservoir method used here. For example, the Richards equation could be solved within the soil of each subwatershed, provided that the computational resources at hand are sufficient. The modularity of StreamFlow would allow for such a modification to be easily integrated into the existing code.
Table 4 presents quantitative error measures of discharge modelled over the validation period at the three gauging points located in the Dischma catchment (see Fig. 4), for the same StreamFlow configuration as in Fig. 6. The accuracy of the benchmark model at the catchment outlet is also indicated in the table for comparison. It should be mentioned that the benchmark model could not be evaluated at the two intermediate stations since the measurement time series at these points extend over less than a year (see Sect. 4.1). As observed in the table, the discharge NSE value associated with the best StreamFlow simulation is larger than 0.80 at all three points, as opposed to the NSE value of the benchmark model not exceeding 0.74 . On the other hand, the values of the NSE $\log$ - defined as NSE computed with the logarithm of the discharge values - are quite comparable between both models. This is not particularly surprising in view of the strong seasonality of the baseflow component of discharge, particularly during the winter season. The NSE log value at point Am Rin is rather low, but should be considered with caution since the discharge gauging curve at this point is rather uncertain (not shown). The bias of StreamFlow is observed to be positive at all three gauging points, which certainly results from the slight overestimation of the rate of water percolating at the bottom of the soil columns in the Alpine3D simulation (see above). Overall, the performance of StreamFlow regarding discharge computation based on the instantaneous water routing scheme can be considered satisfying. Its accuracy is comparable to the one of other existing hydrological models applied over high Alpine catchments (e.g. MacDonald et al., 2014; Schaefli et al., 2014). 
Table 4. Accuracy of the hourly discharge simulations performed by StreamFlow using the instantaneous water routing technique. The performance of the discharge benchmark model is indicated in the last row for comparison. The third column contains the period over which the error measures are computed. NSE log corresponds to the Nash-Sutcliffe efficiency computed with the logarithm of the discharge values.

\begin{tabular}{lllrrrr}
\hline Model & Location & Time period & $\begin{array}{c}\text { RMSE } \\
\left(\mathrm{m}^{3} \mathrm{~s}^{-1}\right)\end{array}$ & $\begin{array}{c}\text { NSE } \\
(-)\end{array}$ & $\begin{array}{c}\text { NSE log } \\
(-)\end{array}$ & $\begin{array}{c}\text { Bias } \\
\left(\mathrm{m}^{3} \mathrm{~s}^{-1}\right)\end{array}$ \\
\hline \multirow{2}{*}{ StreamFlow } & Outlet & entire validation period & 0.60 & 0.82 & 0.90 & 0.14 \\
& Aürboden & 17 Jan to 25 Sep 2015 & 0.30 & 0.81 & 0.91 & 0.11 \\
\hline \multirow{2}{*}{ Benchmark } & Outlet & 17 Jan to 17 Jul 2015 & 0.10 & 0.82 & 0.76 & 0.02 \\
\hline
\end{tabular}
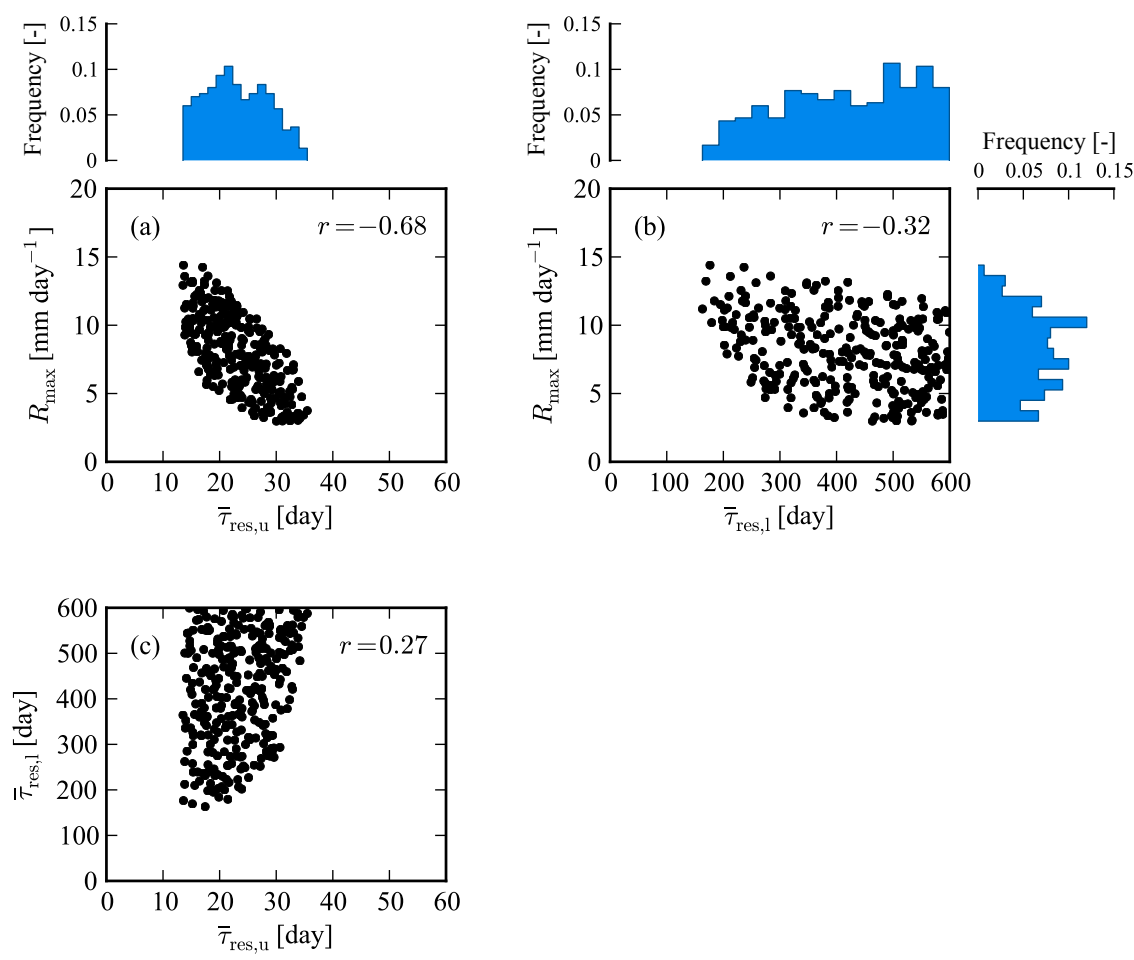

Figure 7. The 300 best sets of StreamFlow parameters associated with water transport (see Table 2 for more information on the parameters). Each panel contains the values of two parameters displayed as a function of each other: (a) $R_{\max }$ versus $\bar{\tau}_{\text {res,l, }}$, (b) $\bar{\tau}_{\text {res,u versus }} \bar{\tau}_{\text {res,1 }}$ and (c) $R_{\max }$ versus $\bar{\tau}_{\text {res,u }}$. Each $x$ or $y$ axis spans the entire calibration range of its associated parameter. The parameter distributions are indicated in blue on the sides of the corresponding panels; for example, the distribution of the 300 best $R_{\max }$ values is shown on the right-hand side of panel (a). Pearson's correlation coefficient $r$ between each pair of parameters is indicated in the upper right-hand corner of the associated graph.

Regarding the calibration parameters, it appears that the values of $R_{\max }$ and $\bar{\tau}_{\text {res,u }}$ are rather well identified (see Fig. 7). Indeed, their respective distributions based on the best 300 parameter sets are contained within a rather narrow interval, clearly separated from the bounds of the respective calibration ranges. Within this interval, however, the two parameters are strongly correlated with one another, as pictured in panel $\mathrm{c}$ of Fig. 7. This points at the equifinality of the parameter sets (Bárdossy, 2007), since an increase in $\bar{\tau}_{\text {res,u }}$ conjugated with a decrease in $R_{\max }$ keeps the model accuracy almost constant. As opposed to $\bar{\tau}_{\text {res,u }}$ and $R_{\max }$, parameter $\bar{\tau}_{\text {res, } 1}$ is associated with a broad distribution, sticking to the upper boundary of the calibration interval (see panel a of Fig. 7). As such, StreamFlow appears to be relatively insensitive to the value of $\bar{\tau}_{\text {res, }, 1}$, as further emphasized by the low correlation between $\bar{\tau}_{\text {res, } 1}$ and the other two parameters (Bárdossy, 2007).

In order to evaluate the influence of the channel water routing scheme on the modelled discharge, StreamFlow was run with the following configurations in complement to the instantaneous routing technique evaluated above: (a) the Muskingum-Cunge approach with lumped stream reaches 


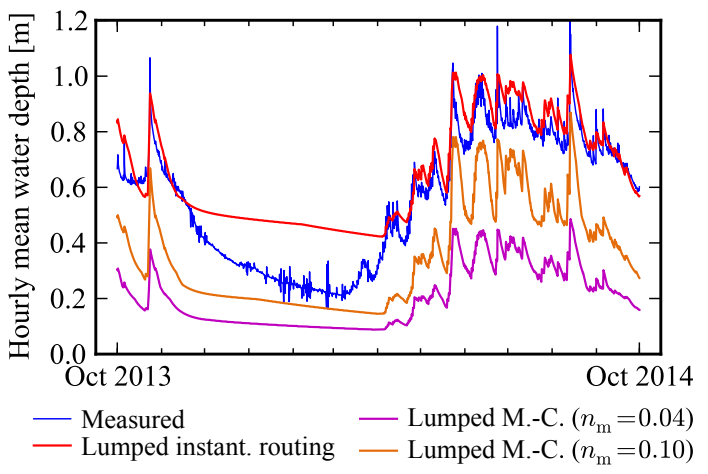

Figure 8. Water depth as simulated by StreamFlow in hydrological year 2014 using various channel water routing techniques. The measured water depth is indicated in blue and shown here only as an indication (see text). Regarding the curves associated with the Muskingum-Cunge routing technique, only those obtained using lumped stream reaches are shown (orange and violet curves). Those corresponding to discretized stream reaches almost overlap with their lumped counterparts, with the difference between each pair of curves amounting to a RMSE of $0.5 \mathrm{~mm}$ for $n_{\mathrm{m}}=0.04$ and $3.9 \mathrm{~mm}$ for $n_{\mathrm{m}}=0.10$ over the entire period 2013-2015.

and Manning's coefficient $n_{\mathrm{m}}$ set to 0.04 ; (b) same as (a) but with $n_{\mathrm{m}}=0.10$; and (c)-(d) same as (a)-(b) but with discretized stream reaches. The chosen values for Manning's coefficient correspond to the lower and upper boundaries of the uncertainty interval estimated in the Dischma catchment based on the work of Phillips and Tadayon (2006). The results indicate that the modelled hourly mean discharge curves in all cases (a) to (d) almost identically correspond to the one depicted in Fig. 6, up to a maximum RMSE of $0.03 \mathrm{~m}^{3} \mathrm{~s}^{-1}$ between all curves over the entire simulated period (not shown). Similarly, the error measures reported in Table 4 are also valid in cases (a) to (d). The routing technique therefore appears to have only a very limited impact on the simulated discharge in the Dischma catchment, which is easily explained by the small size of the watershed (Schaefli et al., 2014). Indeed, the average streamwise distance between the stream cells and the catchment outlet is about $6.6 \mathrm{~km}$, which - assuming a flow velocity of $1 \mathrm{~m} \mathrm{~s}^{-1}$ - corresponds to a mean travel time of about $2 \mathrm{~h}$ down to the catchment outlet. This also explains the observed low sensitivity of StreamFlow to the value of Manning's coefficient in the present case. As expected, the above results suggest that, in small- to medium-sized catchments, the use of spatially discretized stream reaches to simulate discharge is not associated with any marked improvement with respect to the lumped approach.

Albeit discharge is simulated unequivocally by all water routing techniques, water depth and flow velocity are not. As pictured in Fig. 8 for hydrological year 2014, differences between the simulated water depth curves are quite large, with, for example, a RMSE of $44.5 \mathrm{~cm}$ between the curve associated with the instantaneous routing technique and the one corresponding to the Muskingum-Cunge approach with $n_{\mathrm{m}}=0.04$. The instantaneous water routing technique predicts a higher water depth here as compared to the Muskingum-Cunge approach, reflecting the values of the gauging curve coefficients $\alpha_{h}$ and $\beta_{h}$ (see Sect. 2.2.1 and Table 2). In addition, the predictions based on the MuskingumCunge technique depend on the value of Manning's coefficient, as expected from Eq. (7): the higher $n_{\mathrm{m}}$, the higher the simulated water depth. However, as for the case of discharge, the water depth estimations do not appear to benefit from the use of discretized stream reaches as opposed to lumped ones, since both corresponding curves almost overlap for a fixed $n_{\mathrm{m}}$ (see legend of Fig. 8). It should be mentioned that comparison with the measured water depth is hazardous since the modelled river width at the outlet gauging station was not verified to correspond to the observed one. The measured curve is therefore only shown here as an indication. The fact that it diverges from the curve associated with the instantaneous advection approach during winter is due to the fact that the discharge gauging curve of FOEN is linear for small water depth values, and adopts the form of a power function as in StreamFlow only for larger values of $h$. Given that simulated discharge is almost the same for all water routing techniques, the differences in simulated water depth result in large differences in the simulated flow velocity as well (not shown).

\subsubsection{StreamFlow simulations of stream temperature}

Turning now to the stream temperature simulations, we first determine an appropriate value for the soil temperature averaging depth $z_{\mathrm{d}}$ (see Sect. 2.1.2 and Eq. 12). Five different possibilities are considered here: $0.15,0.30,0.60,1.20$ and $2.40 \mathrm{~m}$. Using StreamFlow configured so as to approximate the temperature of the subsurface flux as the depth-averaged soil temperature (Sect. 2.1.2), we find that the choice $z_{\mathrm{d}}=$ $2.40 \mathrm{~m}$ leads to the best results in terms of temperature-based NSE (not shown). This rather large value may be due to the relatively low resolution of the vertical soil temperature profile computed by Alpine3D, which was configured here to use a coarse vertical discretization of the soil columns in order to spare computational power. The value $z_{\mathrm{d}}=2.40 \mathrm{~m}$ is nevertheless used in the remainder of this study, since emphasis is on demonstrating the model capabilities rather than performing particularly accurate simulations. Similarly, it can be observed based on Table 2 that the calibrated values of some stream temperature parameters (notably $k_{\text {soil }}$ and $D_{\mathrm{HSPF}}$ ) are close to the respective upper limits of their associated calibration ranges. For the sake of conciseness, however, we proceed with the parameter values presented in Table 2 and postpone the in-depth evaluation of the model sensitivity with respect to its parameters to a future publication.

Figure 9 displays stream temperature as simulated by StreamFlow over the hydrological years 2013-2015, with 
Table 5. Accuracy of the hourly stream temperature predictions of StreamFlow (with $z_{\mathrm{d}}=2.40 \mathrm{~m}$ ), based on various approaches for advecting water in the stream channels and computing the temperature of the subsurface water flux. The accuracy of the temperature benchmark model at the catchment outlet is indicated in the last row for comparison. All error measures are computed over the entire validation period (1 October 2013 to 1 October 2015), except at points Am Rin and Dürrboden for which the considered time period is the same as in Table 4.

\begin{tabular}{|c|c|c|c|c|c|c|}
\hline Model & Channel water routing scheme ${ }^{a}$ & $\begin{array}{l}\text { Subwatershed outflow } \\
\text { temperature scheme }\end{array}$ & Location & $\begin{array}{r}\text { RMSE } \\
\left({ }^{\circ} \mathrm{C}\right)\end{array}$ & $\begin{array}{r}\mathrm{NSE} \\
(-)\end{array}$ & $\begin{array}{l}\text { Bias } \\
\left({ }^{\circ} \mathrm{C}\right)\end{array}$ \\
\hline \multirow{8}{*}{ StreamFlow } & \multirow[t]{3}{*}{ Instantaneous advection (lumped) } & \multirow[t]{3}{*}{ Soil temperature } & Outlet & 1.45 & 0.78 & -0.88 \\
\hline & & & Dürrboden & 1.45 & 0.78 & 0.75 \\
\hline & & & Am Rin & 1.11 & 0.89 & -0.05 \\
\hline & Instantaneous advection (discr.) & Soil temperature & Outlet & 1.40 & 0.80 & -0.85 \\
\hline & Muskingum-Cunge ( $n_{\mathrm{m}}=0.07$, lumped $)$ & & & 1.49 & 0.77 & -0.85 \\
\hline & Muskingum-Cunge ( $n_{\mathrm{m}}=0.07$, discr.) & & & 1.46 & 0.78 & -0.80 \\
\hline & \multirow[t]{2}{*}{ Instantaneous advection (lumped) } & Energy balance & Outlet & 2.06 & 0.56 & -1.63 \\
\hline & & HSPF & & 1.69 & 0.70 & 0.54 \\
\hline Benchmark & - & - & Outlet & 1.14 & 0.87 & -0.03 \\
\hline
\end{tabular}

\footnotetext{
a The indications "lumped" and "discr." between brackets refer to the spatial discretization of the stream reaches (see Sect. 2.2).

b The schemes described in Sect. 2.1.2 for the computation of the subsurface flux temperature are denoted as follows here: "soil temperature" for the scheme assuming the subsurface flux to be in thermal equilibrium with surrounding soil, "energy balance" for the original scheme implemented in StreamFlow and "HSPF" for the scheme inspired from the Hydrological Simulation Program-Fortran.
}
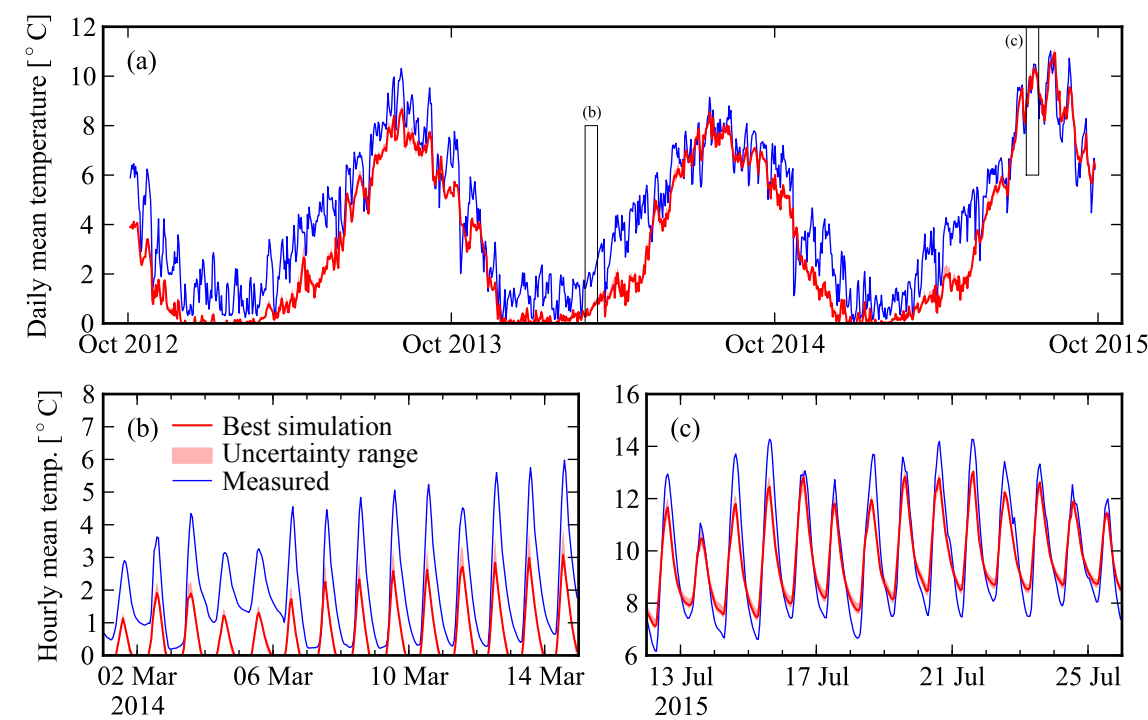

Figure 9. Comparison between the simulated (red line) and measured (blue line) time evolution of stream temperature at the catchment outlet. Panel (a) pictures the entire simulated period (hydrological years 2013 to 2015), with temperature aggregated into daily mean values for visibility. Panels (b) and (c) display the hourly mean temperature over two selected periods of 14 days (their respective extents are indicated as black rectangles in panel a). The simulated curve was obtained with StreamFlow based on the instantaneous water routing scheme, with the temperature of the subsurface water flux being approximated as the soil temperature averaged over a depth of $2.40 \mathrm{~m}$. The uncertainty range (displayed in light red) is obtained by evaluating StreamFlow for each one of the 300 best sets of parameters $R_{\text {max }}, \bar{\tau}_{\text {res,u }}$ and $\bar{\tau}_{\text {res,u }}$ identified during calibration step 1 (see Sect. 4.2).

channel water being advected based on the instantaneous routing scheme and subwatershed outflow temperature being approximated as the depth-averaged soil temperature (same configuration as above). As evident from panel a, stream temperature is generally underestimated by the model on a daily timescale, particularly during the snow melt season in spring. We attribute this discrepancy to soil temperature as simu- lated by Alpine3D being too low, since its value averaged down to $2.40 \mathrm{~m}$ typically remains around $0{ }^{\circ} \mathrm{C}$ until midJune (not shown). This underestimation of soil temperature is in turn expected to result from the coarse soil vertical discretization used in the Alpine3D simulation (see above). As a workaround, the soil temperature averaging depth $z_{\mathrm{d}}$ could be increased, since it would result in larger soil temperature 
Table 6. Values chosen for the parameters of test cases 1 and 2, and used to validate the numerical splitting scheme presented in Sect. 2.2.2.

\begin{tabular}{lll}
\hline Name & Units & Value \\
\hline$\tau$ & $(\mathrm{s})$ & $2 \times 10^{6}$ \\
$\omega$ & $\left(\mathrm{s}^{-1}\right)$ & $2 \pi / 3600$ \\
$a_{\sigma}$ & $\left(\mathrm{K} \mathrm{s}^{-1}\right)$ & $5 \times 10^{-3}$ \\
$b_{\sigma}$ & $\left(\mathrm{K} \mathrm{s}^{-1}\right)$ & $2 \times 10^{-4}$ \\
$a_{v}$ & $\left(\mathrm{~s}^{-1}\right)$ & $1 / 12800$ \\
$b_{v}$ & $\left(\mathrm{~m} \mathrm{~s}^{-1}\right)$ & 0.5 \\
$a_{\text {in }}$ & $(\mathrm{K})$ & 1.5 \\
$b_{\text {in }}$ & $(\mathrm{K})$ & 283.15 \\
\hline
\end{tabular}

values while at the same time not lengthening the computation time of the Alpine3D simulation. This approach is not presented here in more detail in order to keep the article concise, but simply mentioned as a hint to interested readers. Past the snow melt season, soil temperature is modelled by Alpine3D to rapidly increase (not shown), which might explain the better agreement between the simulated and measured stream temperature curves during summer.

Panels b and $\mathrm{c}$ of Fig. 9 present a zoom on two selected periods during winter and summer, respectively. StreamFlow is observed to be capable of simulating the diurnal cycle of stream temperature, albeit its magnitude is in general too low. It should be specified that temperature is cut off at $0^{\circ} \mathrm{C}$ by the model in winter in order to avoid unphysical values. The underestimation of the magnitude of the diurnal cycle may originate from an overestimation of water depth or, equivalently, from an underestimation of the stream width. This hypothesis can unfortunately hardly be tested, since water depth and stream width are difficult to quantify in small mountainous streams with irregular, boulder-covered beds. We verified whether the latent and sensible heat fluxes are not underestimated by StreamFlow. To this end, we increased the values of coefficients $a_{v w}$ and $b_{v w}$ by $50 \%$ (see Eq. 13 and Table 2); however, this did not result in a marked improvement of the simulated diurnal cycle (not shown). The effect of the heat exchange with the stream bed was also tested by reducing the value of $k_{\text {bed }}$ by $50 \%$ (see Eq. 12 and Table 2), but this had almost no impact on the simulated temperature curve either (not shown). The underestimation of the diurnal cycle therefore appears to mostly originate from the approach selected for the modelling of the subsurface flux temperature, as discussed in more detail below. From the inspection of all three panels in Fig. 9, it can be stated that modelled temperature is not particularly affected by the uncertainty in the values of hydrological parameters $R_{\max }, \bar{\tau}_{\text {res,u }}$ and $\bar{\tau}_{\text {res,1. }}$. As a matter of fact, the uncertainty range of the simulated temperature curve remains globally narrow, except around midday where it reaches a value up to $1^{\circ} \mathrm{C}$ on some days (see panel b). This limited sensitivity of modelled temperature with re-

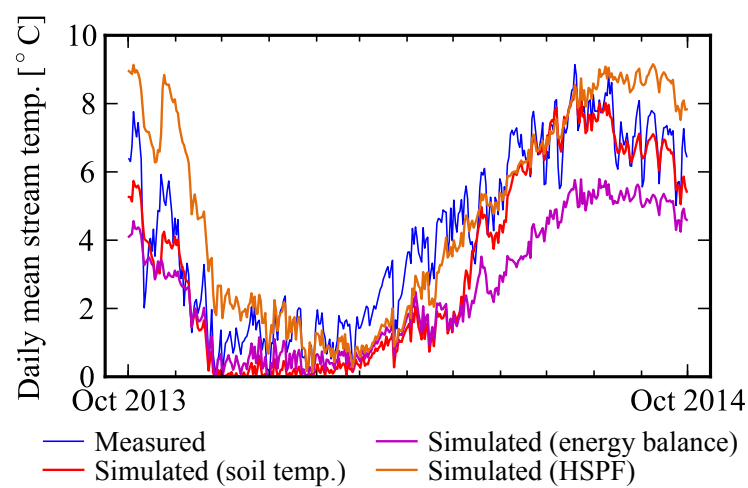

Figure 10. Comparison between various predictions of stream temperature at the catchment outlet, where the temperature of the subsurface water flux is computed based on the following methods: the original scheme implemented in StreamFlow (energy balance), the technique of the Hydrological Simulation Program-Fortran (HSPF), or as soil temperature averaged over a depth of $2.40 \mathrm{~m}$ (soil temp.). All curves are aggregated into daily mean values for visibility.

spect to simulated discharge (and water depth) further hints at the probable role of the subsurface flux temperature on the underestimation of the temperature diurnal cycle.

The values of the error measures associated with Fig. 9 are summarized in Table 5. The NSE value of the hourly mean temperature curve $(0.78)$ is much lower than the one of the benchmark model (0.87), which denotes a strong improvement potential. This has to be put into perspective with the fact that the Dischmabach river is rather small and heavily turbulent, and therefore more challenging to model as compared to larger, low-altitude rivers. In addition, the NSE value is comparable to the one reported by MacDonald et al. (2014) over a mountainous watershed of similar size and altitudinal range as the Dischma catchment. The RMSE equals $1.45^{\circ} \mathrm{C}$, which is not very far from the RMSE of the benchmark model $\left(1.14^{\circ} \mathrm{C}\right)$. On the other hand, the bias is rather large $\left(-0.88^{\circ} \mathrm{C}\right)$, as already noted from the observation of Fig. 9 above. Regarding the model performance at the two intermediate gauging points, the values of the error measures at Dürrboden are found to be essentially the same as at the outlet point, except for the positive bias (see Table 5). The latter indicates that the modelled stream temperatures at these two points are - contrary to the temperature at the outlet point - not underestimated, which results from the fact that the stream temperature values measured at the intermediate points are much closer to the simulated soil temperature curve in spring as compared to the stream temperature measured at outlet point (not shown). Concerning Am Rin, the apparent better values for RMSE, NSE and bias have to be weighted against the short time period over which they are evaluated (17 January to 17 July 2015).

As already discussed above, the simulated stream temperature is not particularly sensitive to the modelled discharge 
(and water depth). This fact is confirmed by the values of the error measures reported in Table 5 for four temperature simulations, each one based on a different water routing scheme, namely the instantaneous advection technique or the Muskingum-Cunge approach, combined with either a lumped or discretized modelling of the stream reaches. In the simulations based on the Muskingum-Cunge approach, Manning's coefficient is fixed to 0.07 , which corresponds to the middle of the above-defined range of plausible values in the case of the Dischmabach river. It appears that all four simulations are associated with a similar accuracy in terms of stream temperature modelling, as indicated by the narrow range of NSE (0.77-0.80) and RMSE (1.40-1.49 $\left.{ }^{\circ} \mathrm{C}\right)$ values. Contrary to the discharge simulations, the discretized representation of the stream reaches here enables a slight improvement of the results as compared to the lumped approach, mainly due to a better resolution of the diurnal cycle (not shown).

In a recent study, Leach and Moore (2015) reviewed the approaches implemented in some of the most popular stream temperature models for approximating the temperature of the subsurface water flux. Based on a comparison with data collected in a small Canadian watershed, they concluded that none of them performed well, except for the method implemented in the HSPF model approaching the observations relatively closely. More interestingly, the authors pointed at large discrepancies between the predictions of the various models. As a further step, we propose here to investigate the effect of the modelled subsurface flux temperature on the simulated stream temperature at the catchment outlet. To this end, three StreamFlow simulations are run with the same configuration as above - namely lumped reaches and the instantaneous routing scheme - except that the temperature of the subsurface flux is computed each time based on a different method out of the three available ones (see Sect. 2.1.2). It should be mentioned that, in virtue of the modular structure of StreamFlow, changing from one method to the next simply requires one line to be modified in the configuration file. The simulation results are displayed in Fig. 10, and the corresponding error measures can be found in Table 5. It can be observed that the approach used to compute the temperature of the subsurface flux has a strong influence on the accuracy of the modelled stream temperature. The method originally implemented in StreamFlow appears to perform worse (NSE of 0.56 , RMSE of $2.06^{\circ} \mathrm{C}$ ), followed by the HSPF approach (NSE of 0.70 , RMSE of $1.69^{\circ} \mathrm{C}$ ). The method based on the depth-averaged soil temperature is associated with the best performance measures (see above). Overall, the three methods seem to determine the temperature of in-stream water to a large extent, leading to variations of more than $4{ }^{\circ} \mathrm{C}$ between the different curves (see Fig. 10). These observations point at the strong need for additional field investigations of the dynamics of the subsurface flux temperature, as already mentioned by Leach and Moore (2015).

\section{Conclusions}

Combined modelling of hydrological and thermodynamic processes offers promising perspectives for the prediction of stream temperature at the catchment scale. The present study describes a new coupled hydrothermal model, named StreamFlow, which is currently intended to be used in high Alpine environments. Designed as an independent extension to the spatially distributed snow model Alpine3D, it has been written entirely anew compared to its initial version. The resulting code has a clear and modular structure which takes advantage of some of the latest available object-oriented features. Several of the hydrological processes represented in the model can be simulated using various alternatives. For example, the advection of water in the stream channels can be computed using either the Muskingum-Cunge technique or an instantaneous routing approach. This modularity enables the model to be adapted to the specific needs of each user, but also provides a rapid means to estimate the uncertainty of the simulation results by comparing the predictions of the various modelling alternatives.

Based on an evaluation over a high Alpine catchment, the model accuracy is shown to be satisfying, with NashSutcliffe efficiencies for the hourly mean discharge and hourly mean temperature being equal to 0.82 and 0.78 , respectively. The various water routing techniques available in StreamFlow do not appear to have a marked effect on the quality of the simulations. On the other hand, it was observed that the approach used to compute the temperature of the subsurface water inflow strongly impacts the simulated stream temperature at the catchment outlet. This effect has not been reported in any previous study and points at the need for more intensive field investigations of the subsurface flux temperature.

Several improvements can be brought to the actual state of the model. The representation of riparian shading would allow StreamFlow to be applied in lower-altitude, vegetated watersheds. However, similarly to the case of the subsurface inflow temperature, the shading by riparian vegetation is a complex phenomenon which is difficult to simulate and requires further research (Moore et al., 2005). The modelling of the ice and snow sheet forming over the stream in winter could also be included in StreamFlow, although little research has been conducted on this subject in high-altitude Alpine streams to date. Finally, additional modelling alternatives could be implemented for various components of StreamFlow, such as the approach developed by Leach and Moore (2015) for the estimation of the subsurface inflow temperature, or the full Saint-Venant equations for the routing of water in the stream channels.

In the near future, we plan to use StreamFlow in order to evaluate the effects of climate change on the hydrological functioning of high Alpine watersheds. In particular, advantage will be taken of the coupled hydrothermal nature of the 
model in order to investigate the impact of the future discharge modifications on stream temperature.

\section{Code availability}

The source code of StreamFlow is available under the GNU Lesser General Public License v3.0 (LGPL v3) at http: $/ /$ models.slf.ch/p/streamflow/ upon creation of a free account. Installation instructions can be found at http://models. slf.ch/p/streamflow/page/Installing-StreamFlow/, and the detailed procedure to launch a StreamFlow simulation at http: //models.slf.ch/p/streamflow/page/Running-StreamFlow/. 


\section{Appendix A: Formulation of the subwatershed linear reservoir model}

This section briefly describes the approaches which were already present in the original version of the code for computing the discharge and temperature of the subsurface flow generated by each subwatershed.

\section{A1 Subwatershed outflow discharge computation}

As illustrated in Fig. A1a, the original model developed by Comola et al. (2015) approximates each subwatershed as the vertical superposition of two linear reservoirs, where the upper one simulates the fast response to rainfall events and the lower one the slow response. Water percolating at the bottom of the subwatershed soil columns fills the lower reservoir up to a maximum flow rate $R_{\max }\left(\mathrm{m} \mathrm{s}^{-1}\right)$, the excess water draining into the upper reservoir. This translates into the following equations for the water levels $S_{\text {res,u }}(\mathrm{m})$ and $S_{\text {res,l }}(\mathrm{m})$ in the upper and lower reservoirs, respectively:

$$
\begin{aligned}
& \frac{\mathrm{d} S_{\text {res }, \mathrm{u}}}{\mathrm{d} t}=I_{\mathrm{res}, \mathrm{u}}-\frac{Q_{\mathrm{res}, \mathrm{u}}}{A_{\text {subw }}}, \\
& \frac{\mathrm{d} S_{\text {res }, 1}}{\mathrm{~d} t}=I_{\mathrm{res}, 1}-\frac{Q_{\text {res }, 1}}{A_{\text {subw }}},
\end{aligned}
$$

where the water inflow rates $I_{\text {res,u }}\left(\mathrm{m} \mathrm{s}^{-1}\right)$ and $I_{\text {res, }, ~}\left(\mathrm{~m} \mathrm{~s}^{-1}\right)$ into the upper and lower reservoirs are expressed as $I_{\text {res,u }}=$ $I-I_{\text {res,l }}$ and $I_{\text {res }, 1}=\min \left(I, R_{\max }\right)$, with $I\left(\mathrm{~m} \mathrm{~s}^{-1}\right)$ denoting the total flow rate of water percolating at the bottom of the subwatershed soil columns and $A_{\text {subw }}\left(\mathrm{m}^{2}\right)$ the subwatershed surface area. $Q_{\text {res,u }}\left(\mathrm{m}^{3} \mathrm{~s}^{-1}\right)$ and $Q_{\text {res, } \mathrm{d}}\left(\mathrm{m}^{3} \mathrm{~s}^{-1}\right)$ correspond to the discharge at the outlet of the upper and lower reservoirs, which are linearly related to the reservoir water levels,

$$
\begin{gathered}
Q_{\text {res }, \mathrm{u}}=A_{\text {subw }} \frac{S_{\text {res,u }}}{\tau_{\text {res,u }}}, \\
Q_{\text {res }, 1}=A_{\text {subw }} \frac{S_{\text {res }, 1}}{\tau_{\text {res }, 1}} .
\end{gathered}
$$

The characteristic residence times $\tau_{\text {res,u }}(\mathrm{s})$ and $\tau_{\text {res, } 1}(\mathrm{~s})$ are expressed as power functions of the subwatershed area:

$$
\begin{aligned}
\tau_{\text {res }, \mathrm{u}} & =\bar{\tau}_{\text {res }, \mathrm{u}}\left(\frac{A_{\text {subw }}}{A_{\text {tot }}}\right)^{\frac{1}{3}}, \\
\tau_{\text {res }, 1} & =\bar{\tau}_{\text {res }, 1}\left(\frac{A_{\text {subw }}}{A_{\text {tot }}}\right)^{\frac{1}{3}},
\end{aligned}
$$

where $\bar{\tau}_{\text {res,u }}(\mathrm{s})$ and $\bar{\tau}_{\text {res,1 }}$ (s) are two user-specified parameters and $A_{\text {tot }}\left(\mathrm{m}^{2}\right)$ denotes the area of the entire parent watershed. The total discharge $Q_{\text {subw }}\left(\mathrm{m}^{3} \mathrm{~s}^{-1}\right)$ flowing from the subwatershed into the stream is then computed as $Q_{\text {subw }}=$ $Q_{\text {res,u }}+Q_{\text {res,l }}$. The subwatershed behaviour can be adjusted by modifying the values of parameters $R_{\max }, \bar{\tau}_{\text {res,u }}$ and $\bar{\tau}_{\text {res, }, 1}$.
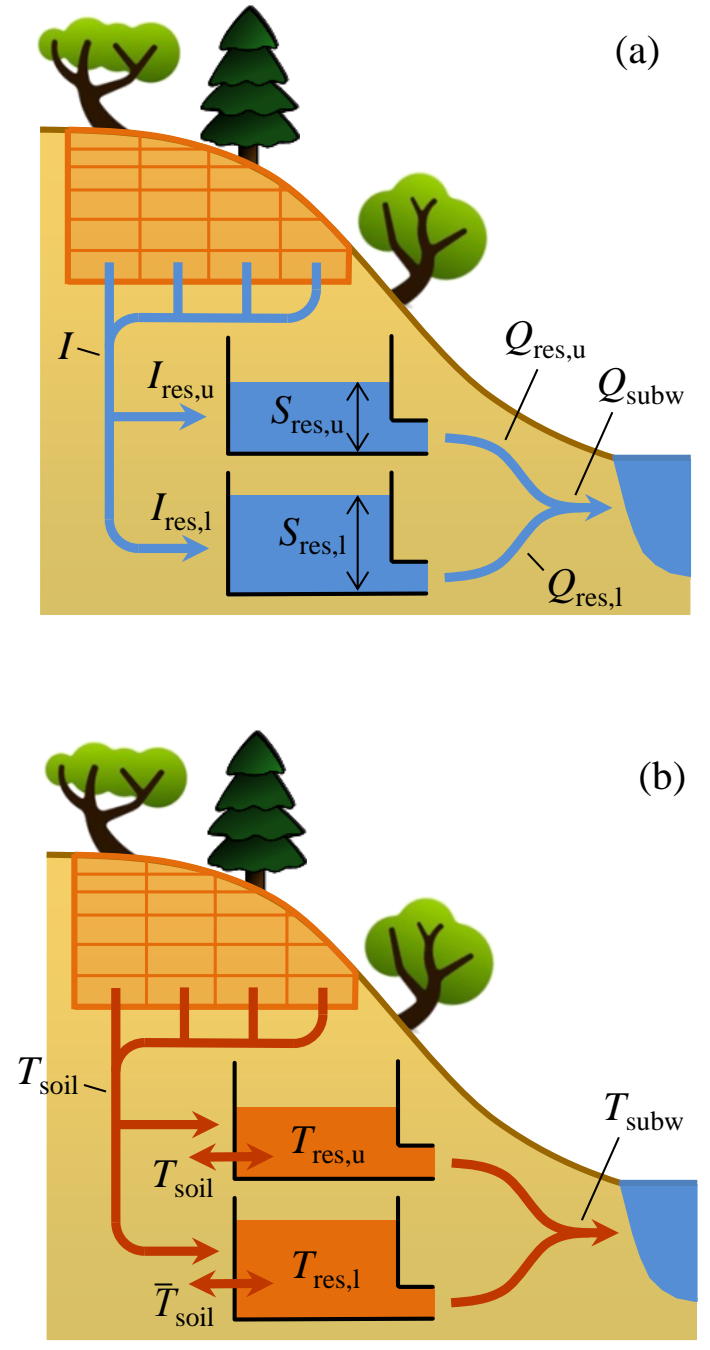

Figure A1. Illustrations of the models devised by Comola et al. (2015) for the computation of (a) subsurface flux discharge and (b) subsurface flux temperature. The symbols are defined in the text.

\section{A2 Subwatershed outflow temperature computation}

The method developed by Comola et al. (2015) for the computation of the subwatershed outflow temperature $T_{\text {subw }}(\mathrm{K})$ is depicted in Fig. A1b. Temperatures $T_{\text {res,u }}(\mathrm{K})$ and $T_{\text {res, }, 1}(\mathrm{~K})$ of water stored in the upper and lower reservoirs are computed as

$$
\begin{aligned}
\frac{\mathrm{d} T_{\text {res,u }}}{\mathrm{d} t}=\frac{I_{\text {res,u }}}{S_{\text {res,u }}}\left(T_{\text {soil }}-T_{\text {res }, \mathrm{u}}\right)+\frac{T_{\text {soil }}-T_{\text {res }, \mathrm{u}}}{k_{\text {soil }}}, \\
\frac{\mathrm{d} T_{\text {res,1 }}}{\mathrm{d} t}=\frac{I_{\text {res }, 1}}{S_{\text {res }, 1}}\left(T_{\text {soil }}-T_{\text {res }, 1}\right)+\frac{\bar{T}_{\text {soil }}-T_{\text {res,u }}}{k_{\text {soil }}},
\end{aligned}
$$

where $k_{\text {soil }}(\mathrm{s})$ is a calibration parameter corresponding to the characteristic time of thermal diffusion and $T_{\text {soil }}(\mathrm{K})$ refers to soil temperature at the bottom of the subwatershed soil columns as modelled by Alpine3D. $\bar{T}_{\text {soil }}$ denotes the annual 
average of $T_{\text {soil }}$, which is used as a proxy for the temperature of deep soil. The first term on the right hand-side of the above two expressions accounts for the heat flux associated with the inflow of water into the reservoirs. The second term corresponds to the diffusive heat exchange between water and the surrounding soil particles. These expressions were derived by assuming that the temperature of water percolating at the bottom of the soil columns is equal to the local soil temperature. They are solved using a second-order Crank-Nicolson scheme, and their solution is used to compute $T_{\text {subw }}(\mathrm{K})$ as the weighted average of $T_{\text {res,u }}$ and $T_{\text {res, }, 1}$ :

$$
T_{\mathrm{subw}}=\frac{Q_{\mathrm{res}, \mathrm{u}} T_{\mathrm{res}, \mathrm{u}}+Q_{\mathrm{res}, 1} T_{\mathrm{res}, 1}}{Q_{\mathrm{res}, \mathrm{u}}+Q_{\mathrm{res}, 1}}
$$

\section{Appendix B: Validation of the splitting scheme used to solve the heat-balance equation}

The splitting scheme described in Sect. 2.2.2 for numerically solving Eq. (11) is validated here by comparing its predictions against analytical solutions. The derivation of the analytical solutions is presented first, followed by the assessment the numerical scheme precision.

\section{B1 Analytical solutions to the heat-balance equation}

Equation (11) can be written in a more compact form:

$\frac{\partial T_{w}}{\partial x}+v \frac{\partial T_{w}}{\partial x}=\frac{1}{\tau} T_{w}+\sigma$,

with

$$
\begin{aligned}
\tau & =-\frac{h w}{q_{\text {subw }}}, \\
\sigma & =\frac{\phi}{\rho_{\mathrm{w}} c_{\mathrm{p}, \mathrm{w}} h}+\frac{q_{\text {subw }}}{h w} T_{\text {subw }}+\frac{g Q}{c_{\mathrm{p}, \mathrm{w}} h w} S_{0} .
\end{aligned}
$$

Similarly to, e.g. Lowney (2000), Eq. (B1) above is simplified by assuming $\tau$ to be constant and $\sigma$ to be a sole function of time. The length of the spatial domain over which the equation is to be solved is denoted as $L$. It is assumed that $v>0$ for all $x \in[0, L]$, so that a boundary condition must be specified at $x=0$. A Dirichlet boundary condition is considered here:

$T_{w}(0, t)=T_{\text {in }}(t) \quad$ for all $t \geqslant 0$,

where $T_{\text {in }}(t)$ is a prescribed function of time. Since the spatial domain is finite, the analytical solution to Eq. (B1), subject to boundary condition Eq. (B2), will consist of a transient phase followed by a permanent regime. During the transient phase, the initial temperature distribution $T_{\mathrm{w}, \text { ini }}(x, t)$ is advected towards the right end of the spatial domain, while the boundary condition $T_{\text {in }}$ dictates the value of temperature entering the domain through its left-hand end. After the last remnant of the initial temperature distribution has exited the spatial domain, the solution reaches its permanent regime, which is the same regardless of the initial distribution. Only the permanent regime is considered here, so that no initial condition needs to be specified.

The analytical solution to Eqs. (B1)-(B2), under the conditions $\tau=$ cst and $\sigma=\sigma(t)$, is obtained by the method of characteristics (e.g. LeVeque, 2002). The two independent variables $x$ and $t$ are parametrized as a function of a path variable $s$. Using the definition $\theta(s)=T(x(s), t(s))$, we observe that

$\frac{\mathrm{d} \theta}{\mathrm{d} s}=\frac{\partial T_{w}}{\partial t} \frac{\mathrm{d} t}{\mathrm{~d} s}+\frac{\partial T_{w}}{\partial x} \frac{\mathrm{d} x}{\mathrm{~d} s}$,

so that Eq. (11) can be rewritten as

$\frac{\mathrm{d} \theta}{\mathrm{d} s}=\frac{1}{\tau} \theta+\sigma$,

if the parameterizations of $x$ and $t$ are chosen such that

$\frac{\mathrm{d} t}{\mathrm{~d} s}=1$,
$\frac{\mathrm{d} x}{\mathrm{~d} s}=v$.

Equation (B3) is an ordinary differential equation in which $\sigma$ should be understood as a function of $s$, i.e. $\sigma(s)=\sigma(t(s))$. Its solution can be easily found and is given by

$\theta(s)=\int_{s_{0}}^{s}\left(\sigma\left(s^{\prime}\right)+\frac{\theta\left(s_{0}\right)}{\tau}\right) \exp \left(\frac{s-s^{\prime}}{\tau}\right) \mathrm{d} s^{\prime}+\theta\left(s_{0}\right)$,

where $s_{0}$ denotes the lower integration bound, which needs to be specified. Equation (B4) is trivially solved through integration between $s_{0}$ and $s$ :

$t(s)=s+s_{0}-t_{0}$,

where $t_{0}=t\left(s_{0}\right)$. The above expression for $t$ implies that $s$ is equivalent to time (i.e. $s \equiv t$ ), so that $x$ can be interpreted as the position of a particle moving with instantaneous velocity $v$ as per Eq. (B5). In the permanent regime, each "particle" enters the spatial domain through its left-hand side boundary. As a consequence, $s_{0}-$ or, equivalently, $t_{0}$ - needs to be chosen such that $x\left(s_{0}\right)=0$ in the present case. This further implies that

$\theta\left(s_{0}\right)=T_{w}\left(x\left(s_{0}\right), t\left(s_{0}\right)\right)=T_{w}\left(0, t_{0}\right)=T_{\text {in }}\left(t_{0}\right)$,

where Eq. (B2) has been used in the last step. Inserting the above expression in Eq. (B6) and replacing $\theta(s)$ with $T_{w}(x, t)$ and $s$ with $t$, one finally obtains

$$
\begin{aligned}
T_{w}(x, t)=\int_{t_{0}}^{t} & \left(\sigma\left(t^{\prime}\right)+\frac{T_{\text {in }}\left(t_{0}\right)}{\tau}\right) \exp \left(\frac{t-t^{\prime}}{\tau}\right) \mathrm{d} s^{\prime} \\
& +T_{\text {in }}\left(t_{0}\right) .
\end{aligned}
$$



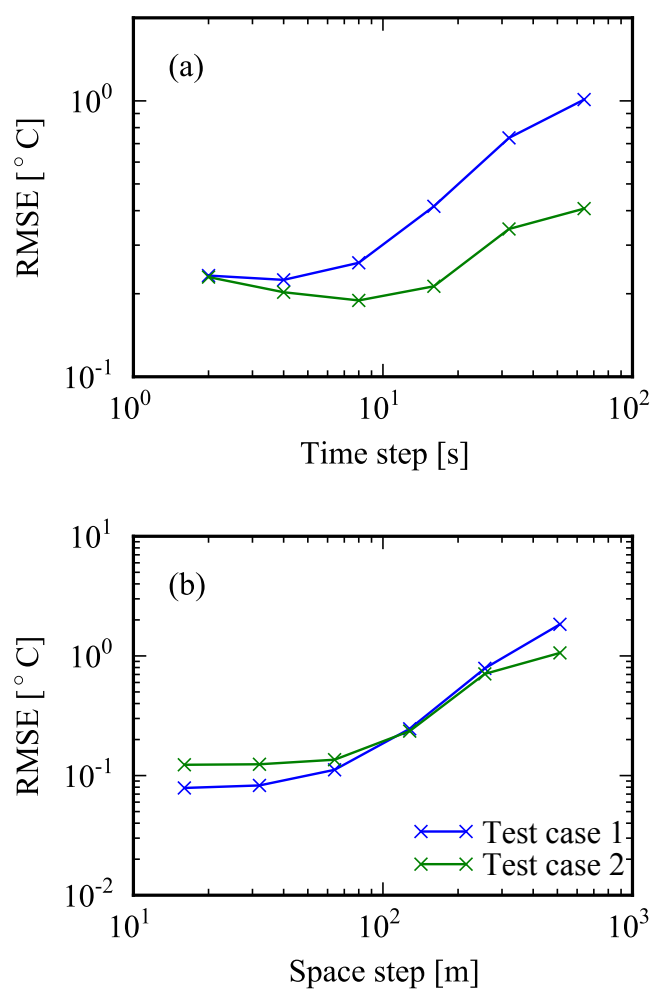

Figure B1. Root mean square error (RMSE) of the splitting scheme used to solve the heat-balance equation in test cases 1 (blue) and 2 (green). The RMSE is computed by comparing the simulated and analytical temperature profiles at the end of the simulation $(8 \mathrm{~h})$. Panel (a) indicates the splitting scheme RMSE for various time steps with a fixed spatial discretization length of $128 \mathrm{~m}$, and (b) the splitting scheme RMSE for various spatial discretization lengths with a fixed time step of $1 \mathrm{~s}$.

Closed-form expressions of the above equation can be found by choosing simple formulations for $\sigma$ and $v$. Two cases are considered here:

Test case 1: Constant velocity and sinusoidal expression for $\sigma:$

$v(x, t)=\mathrm{cst}, \quad$ for all $x \in[0, L], t \geqslant 0$,

$\sigma(t)=a_{\sigma} \sin (\omega t)+b_{\sigma}, \quad$ for all $t \geqslant 0$,

with $\omega\left(\mathrm{s}^{-1}\right), a_{\sigma}\left(\mathrm{K} \mathrm{s}^{-1}\right)$ and $b_{\sigma}\left(\mathrm{K} \mathrm{s}^{-1}\right)$ constant. This test aims at assessing the ability of the splitting scheme to correctly account for time-varying heat sources.

Test case 2: Velocity varying linearly in space and no $\sigma$ term:

$v(x, t)=a_{v} x+b_{v}, \quad$ for all $x \in[0, L], t \geqslant 0$,

$\sigma(t)=0$,

for all $t \geqslant 0$,

where $a_{v}\left(\mathrm{~s}^{-1}\right)$ and $b_{v}\left(\mathrm{~m} \mathrm{~s}^{-1}\right)$ are constant and chosen such that $v>0$ for all $x \in[0, L]$. This test intends
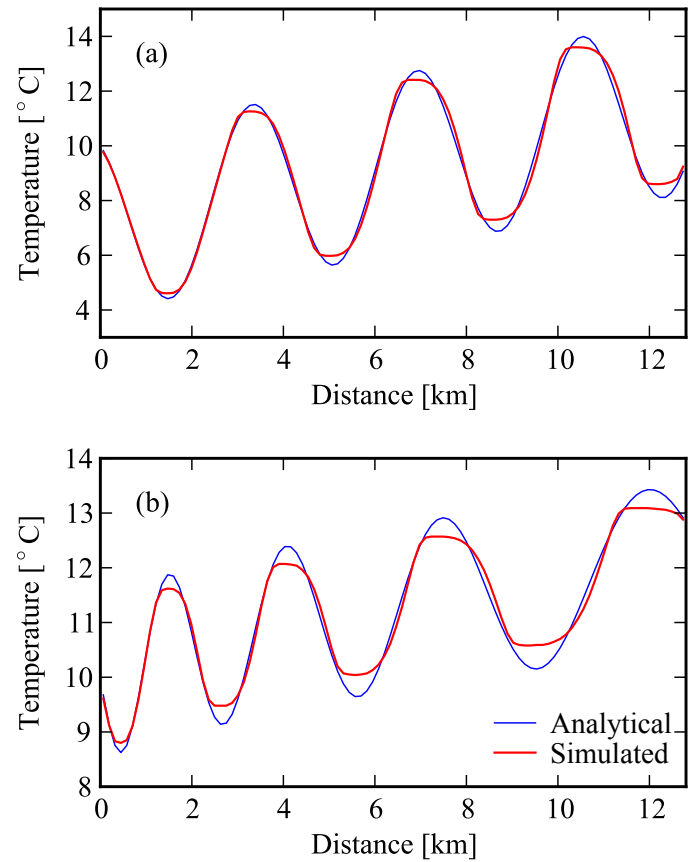

Figure B2. Stream temperature profile at the end of the simulation $(8 \mathrm{~h})$ in (a) test case 1 and (b) test case 2 . The analytical temperature profiles are displayed in blue, and those simulated by the splitting scheme in red.

to validate the robustness of the splitting scheme in the case of non-uniform flow velocity profiles.

In both cases, the expression of $T_{\text {in }}$ is chosen similarly to the one of, e.g. Lowney (2000), who aimed at reproducing natural diurnal variations of stream temperature,

$T_{\text {in }}(t)=a_{\text {in }} \sin (\omega t)+b_{\text {in }}$,

where $a_{\text {in }}(\mathrm{K})$ and $b_{\text {in }}(\mathrm{K})$ are constant, and $\omega$ is the same as in Eq. (B10).

\section{B1.1 Analytical solution of test case 1}

In test case 1, the solution to Eq. (B5) under the constraint $x\left(s_{0}\right)=0$ is straightforward due to $v$ being constant:

$x(s)=v\left(s-s_{0}\right)$.

Replacing $s$ with $t$ and solving for $t_{0}$, one obtains

$t_{0}=t-\frac{x}{v}$

After inserting this expression in Eq. (B8), replacing $\sigma$ with its sinusoidal formulation and performing the integration, one gets the closed-form expression of the solution to 
Eq. (11) in the permanent regime (i.e. for $t>L / v$ ):

$$
\begin{aligned}
T_{w}(x, t)= & T_{\text {in }}\left(t-\frac{x}{v}\right) \exp \left(\frac{x}{\tau v}\right)+b_{\sigma} \tau\left[\exp \left(\frac{x}{\tau v}\right)-1\right] \\
& -\frac{a_{\sigma} \tau}{1+(\tau \omega)^{2}}(\sin (\omega t)+\tau \omega \cos (\omega t)) \\
& +\frac{a_{\sigma} \tau}{1+(\tau \omega)^{2}}\left(\sin \left[\omega\left(t-\frac{x}{v}\right)\right]\right. \\
& \left.+\tau \omega \cos \left[\omega\left(t-\frac{x}{v}\right)\right]\right) \exp \left(\frac{x}{\tau v}\right),
\end{aligned}
$$

with $T_{\text {in }}$ as defined in Eq. (B13). It should be mentioned that the above expression is actually valid for any formulation of $T_{\text {in }}$, not just Eq. (B13).

\section{B1.2 Analytical solution of test case 2}

In case $v$ is expressed as in Eq. (B11), the solution to Eq. (B5) satisfying $x\left(s_{0}\right)=0$ becomes

$x(s)=\frac{b_{v}}{a_{v}}\left(\exp \left[a_{v}\left(s-s_{0}\right)\right]-1\right)$.

The expression for $t_{0}$ is obtained by replacing $s$ with $t$ in the above equation:

$t_{0}=t-\frac{1}{a_{v}} \ln \left(\frac{a_{v}}{b_{v}} x+1\right)$.

The analytical solution of test case 2 is obtained by inserting the above expression for $t_{0}$ in Eq. (B8), imposing $\sigma=0$ and performing the integration

$T_{w}(x, t)=T_{\text {in }}\left(t-\frac{1}{a_{v}} \ln \left(\frac{a_{v}}{b_{v}} x+1\right)\right)\left(\frac{a_{v}}{b_{v}} x+1\right)^{1 /\left(a_{v} \tau\right)}$.

The above solution describes the permanent regime, i.e. it is valid for all $t \geqslant \ln \left(a_{v} L / b_{v}+1\right) / a_{v}$. As opposed to the solution of test case 1, which has already been reported by Lowney (2000), the present one has - to the best of our knowledge not been presented in any publication to date.

\section{B2 Validation of the numerical splitting scheme}

The splitting scheme is validated over a spatial domain of $L=12.8 \mathrm{~km}$, for a simulated time period of $8 \mathrm{~h}$. Table $6 \mathrm{con}-$ tains the values of the parameters considered in test cases 1 and 2.

Figure B1 shows the RMSE of the splitting scheme compared to the analytical solutions of both test cases, for various time steps and spatial discretization lengths. Based on the RMSE values associated with test case 1 , it can be suggested that the scheme is of first order in time and second order in space, as expected from its formulation (see Sect. 2.2.2). This is, however, less visible in test case 2, probably as a result of the RMSE varying over a smaller range of time steps and spatial discretizations lengths as in the first case. In all cases, however, the scheme RMSE remains within acceptable bounds. As can be observed in Fig. B2, the numerical scheme is also able to satisfactorily reproduce the strong fluctuations of the temperature profile in both test cases, except for the minima and maxima which are truncated. 
Author contributions. A. Gallice rewrote and enhanced StreamFlow based on the original code developed by F. Comola, performed the analysis, produced the figures and wrote the manuscript. M. Bavay helped designing the structure of StreamFlow, wrote the CMake scripts to compile the code and set up the CTest environment. He also provided much appreciated guidance on MeteoIO usage and various aspects of $\mathrm{C}++$ coding. T. Brauchli installed the two intermediate gauging stations in the Dischma catchment, performed the salt dilution gaugings and helped a lot in setting up the Alpine3D simulation. F. Comola gave much help regarding the structure and usage of the original version of StreamFlow and suggested some of the analyses presented in this work. All co-authors helped write the manuscript, and H. Huwald and M. Lehning co-supervised the work.

Acknowledgements. This work was financially supported by the Swiss Federal Office for the Environment (FOEN), which is also greatly acknowledged for the free access to its hydrological data. All plots have been produced with the Matplotlib Python library (Hunter, 2007).

Edited by: J. Neal

Reviewed by: two anonymous referees

\section{References}

Aschwanden, H. and Weingartner, R.: Die Abflussregimes der Schweiz, Publikation gewässerkunde nr. 65, Geographisches Institut der Universität Bern, 1985.

Bárdossy, A.: Calibration of hydrological model parameters for ungauged catchments, Hydrol. Earth Syst. Sci., 11, 703-710, doi:10.5194/hess-11-703-2007, 2007.

Barnett, T., Adam, J., and Lettenmaier, D.: Potential impacts of a warming climate on water availability in snow-dominated regions, Nature, 438, 303-309, doi:10.1038/nature04141, 2005.

Bartelt, P. and Lehning, M.: A physical SNOWPACK model for the Swiss avalanche warning. Part I: numerical model, Cold Reg. Sci. Technol., 35, 123-145, doi:10.1016/S0165-232X(02)000745, 2002.

Bavay, M. and Egger, T.: MeteoIO 2.4.2: a preprocessing library for meteorological data, Geosci. Model Dev., 7, 3135-3151, doi:10.5194/gmd-7-3135-2014, 2014.

Bavay, M., Lehning, M., Jonas, T., and Löwe, H.: Simulations of future snow cover and discharge in Alpine headwater catchments, Hydrol. Process., 23, 95-108, doi:10.1002/hyp.7195, 2009.

Bavay, M., Grünewald, T., and Lehning, M.: Response of snow cover and runoff to climate change in high Alpine catchments of Eastern Switzerland, Adv. Water Resour/, 55, 4-16, doi:10.1016/j.advwatres.2012.12.009, 2013.

Beniston, M.: Impacts of climatic change on water and associated economic activities in the Swiss Alps, J. Hydrol., 412-413, 291296, doi:10.1016/j.jhydrol.2010.06.046, 2012.

Berger, M., Aftosmis, M. J., and Murman, S. M.: Analysis of Slope Limiters on Irregular Grids, in: 43rd AIAA Aerospace Sciences Meeting, Reno, NV, USA, nAS Technical Report NAS-05-007, 2005 .
Beven, K. and Binley, A.: The future of distributed models: Model calibration and uncertainty prediction, Hydrol. Process., 6, 279298, doi:10.1002/hyp.3360060305, 1992.

Beven, K. J.: Rainfall-Runoff Modelling: The Primer, 2nd Edn., Wiley-Blackwell, 2012.

Bicknell, B. R., Imhoff, J. C., Kittle, J. L., Donigian, A. S., and Johanson, R. C.: Hydrological Simulation Program-FORTRAN User's Manual for Version 11, U.S. Environmental Protection Agency, National Exposure Research Laboratory, Athens, GA, USA, 1997.

Booch, G., Rumbaugh, J., and Jacobson, I.: The Unified Modeling Language User Guide, 2nd Edn., Addison-Wesley Professional, 2005.

Bürger, G., Schulla, J., and Werner, A. T.: Estimates of future flow, including extremes, of the Columbia River headwaters, Water Resour. Res., 47, W10520, doi:10.1029/2010WR009716, 2011.

Butman, D. and Raymond, P.: Significant efflux of carbon dioxide from streams and rivers in the United States, Nat. Geosci., 4, 839-842, doi:10.1038/ngeo1294, 2011.

Caissie, D.: The thermal regime of rivers: a review, Freshwater Biol., 51, 1389-1406, doi:10.1111/j.1365-2427.2006.01597.x, 2006.

Caldwell, R. J., Gangopadhyay, S., Bountry, J., Lai, Y., and Elsner, M. M.: Statistical modeling of daily and subdaily stream temperatures: Application to the Methow River Basin, Washington, Water Resour. Res., 49, 4346-4361, doi:10.1002/wrcr.20353, 2013.

Chen, Y., Carsel, R., McCutcheon, S., and Nutter, W.: Stream Temperature Simulation of Forested Riparian Areas: I. WatershedScale Model Development, J. Environ. Eng., 124, 304-315, doi:10.1061/(ASCE)0733-9372(1998)124:4(304), 1998.

Comola, F., Schaefli, B., Rinaldo, A., and Lehning, M.: Thermodynamics in the hydrologic response: Travel time formulation and application to Alpine catchments, Water Resour. Res., 51, 16711687, doi:10.1002/2014WR016228, 2015.

Cunge, J. A.: On the subject of a flood propagation computation method (Muskingum method), J. Hydraul. Res., 7, 205-230, doi:10.1080/00221686909500264, 1969.

Elliott, J. M. and Elliott, J. A.: Temperature requirements of Atlantic salmon Salmo salar, brown trout Salmo trutta and Arctic charr Salvelinus alpinus: predicting the effects of climate change, J. Fish Biol., 77, 1793-1817, doi:10.1111/j.10958649.2010.02762.x, 2010.

Fatichi, S., Rimkus, S., Burlando, P., Bordoy, R., and Molnar, P.: High-resolution distributed analysis of climate and anthropogenic changes on the hydrology of an Alpine catchment, J. Hydrol., 525, 362-382, doi:10.1016/j.jhydrol.2015.03.036, 2015.

Ferrari, M. R., Miller, J. R., and Russell, G. L.: Modeling changes in summer temperature of the Fraser River during the next century, J. Hydrol., 342, 336-346, doi:10.1016/j.jhydrol.2007.06.002, 2007.

Ficklin, D. L., Luo, Y., Stewart, I. T., and Maurer, E. P.: Development and application of a hydroclimatological stream temperature model within the Soil and Water Assessment Tool, Water Resour. Res., 48, W01511, doi:10.1029/2011WR011256, 2012.

Ficklin, D. L., Barnhart, B. L., Knouft, J. H., Stewart, I. T., Maurer, E. P., Letsinger, S. L., and Whittaker, G. W.: Climate change and stream temperature projections in the Columbia River basin: habitat implications of spatial variation in hydrologic drivers, 
Hydrol. Earth Syst. Sci., 18, 4897-4912, doi:10.5194/hess-184897-2014, 2014.

Finger, D., Heinrich, G., Gobiet, A., and Bauder, A.: Projections of future water resources and their uncertainty in a glacierized catchment in the Swiss Alps and the subsequent effects on hydropower production during the 21 st century, Water Resour. Res., 48, W02521, doi:10.1029/2011WR010733, 2012.

Gallice, A., Schaefli, B., Lehning, M., Parlange, M. B., and Huwald, H.: Stream temperature prediction in ungauged basins: review of recent approaches and description of a new physicsderived statistical model, Hydrol. Earth Syst. Sci., 19, 37273753, doi:10.5194/hess-19-3727-2015, 2015.

Gamma, E., Helm, R., Johnson, R., and Vlissides, J.: Design patterns: elements of reusable object-oriented software, AddisonWesley, 1994.

Goodison, B., Louie, P., and Yang, D.: WMO Solid Precipitation Measurement Intercomparison, Tech. Rep. WMO/TD-No. 872, IOM No. 67, World Meteorological Organization, 1998.

Gouttevin, I., Lehning, M., Jonas, T., Gustafsson, D., and Mölder, M.: A two-layer canopy model with thermal inertia for an improved snowpack energy balance below needleleaf forest (model SNOWPACK, version 3.2.1, revision 741), Geosci. Model Dev., 8, 2379-2398, doi:10.5194/gmd-8-2379-2015, 2015.

Grillakis, M. G., Tsanis, I. K., and Koutroulis, A. G.: Application of the HBV hydrological model in a flash flood case in Slovenia, Nat. Hazards Earth Syst. Sci., 10, 2713-2725, doi:10.5194/nhess-10-2713-2010, 2010.

Groot Zwaaftink, C. D., Mott, R., and Lehning, M.: Seasonal simulation of drifting snow sublimation in Alpine terrain, Water Resour. Res., 49, 1581-1590, doi:10.1002/wrcr.20137, 2013.

Haag, I. and Luce, A.: The integrated water balance and water temperature model LARSIM-WT, Hydrol. Process., 22, 1046-1056, doi:10.1002/hyp.6983, 2008.

Hannah, D. M., Malcolm, I. A., Soulsby, C., and Youngson, A. F.: Heat exchanges and temperatures within a salmon spawning stream in the Cairngorms, Scotland: seasonal and sub-seasonal dynamics, River Res. Appl., 20, 635-652, doi:10.1002/rra.771, 2004.

Hari, R. E., Livingstone, D. M., Siber, R., Burkhardt-Holm, P., and Güttinger, H.: Consequences of climatic change for water temperature and brown trout populations in Alpine rivers and streams, Glob. Change Biol., 12, 10-26, doi:10.1111/j.13652486.2005.001051.x, 2006.

Hauer, F. R., Baron, J. S., Campbell, D. H., Fausch, K. D., Hostetler, S. W., Leavesley, G. H., Leavitt, P. R., McKnight, D. M., and Stanford, J. A.: Assessment of climate change and freshwater ecosystems of the rocky mountains, usa and canada, Hydrol. Process., 11, 903-924, doi:10.1002/(SICI)10991085(19970630)11:8<903::AID-HYP511>3.0.CO;2-7, 1997.

Hébert, C., Caissie, D., Satish, M., and El-Jabi, N.: Predicting hourly stream temperatures using the equilibrium temperature model, Journal of Water Resource and Protection, 7, 322-338, doi:10.4236/jwarp.2015.74026, 2015.

Hunter, J. D.: Matplotlib: A 2D graphics environment, Comput. Sci. Eng., 9, 90-95, 2007.

Isaak, D. J., Young, M. K., Luce, C. H., Hostetler, S. W., Wenger, S. J., Peterson, E. E., Ver Hoef, J. M., Groce, M. C., Horan, D. L., and Nagel, D. E.: Slow climate velocities of mountain streams portend their role as refugia for cold- water biodiversity, P. Natl. Acad. Sci. USA, 113, 4374-4379, doi:10.1073/pnas.1522429113, 2016.

Khakbaz, B., Imam, B., Hsu, K., and Sorooshian, S.: From lumped to distributed via semi-distributed: Calibration strategies for semi-distributed hydrologic models, J. Hydrol., 418-419, 61-77, doi:10.1016/j.jhydrol.2009.02.021, 2012.

Kormann, C., Francke, T., and Bronstert, A.: Detection of regional climate change effects on alpine hydrology by daily resolution trend analysis in Tyrol, Austria, J. Water Clim. Change, 6, 124143, doi:10.2166/wcc.2014.099, 2015a.

Kormann, C., Francke, T., Renner, M., and Bronstert, A.: Attribution of high resolution streamflow trends in Western Austria an approach based on climate and discharge station data, Hydrol. Earth Syst. Sci., 19, 1225-1245, doi:10.5194/hess-19-12252015, 2015b.

Leach, J. A. and Moore, R. D.: Observations and modeling of hillslope throughflow temperatures in a coastal forested catchment, Water Resour. Res., 51, 3770-3795, doi:10.1002/2014WR016763, 2015.

Lehning, M., Bartelt, P., Brown, B., Russi, T., Stöckli, U., and Zimmerli, M.: SNOWPACK model calculations for avalanche warning based upon a new network of weather and snow stations, Cold Reg. Sci. Technol., 30, 145-157, doi:10.1016/S0165232X(99)00022-1, 1999.

Lehning, M., Bartelt, P., Brown, B., and Fierz, C.: A physical SNOWPACK model for the Swiss avalanche warning. Part III: meteorological forcing, thin layer formation and evaluation, Cold Reg. Sci. Technol., 35, 169-184, doi:10.1016/S0165232X(02)00072-1, 2002a.

Lehning, M., Bartelt, P., Brown, B., Fierz, C., and Satyawali, P.: A physical SNOWPACK model for the Swiss avalanche warning. Part II: Snow microstructure, Cold Reg. Sci. Technol., 35, 147167, doi:10.1016/S0165-232X(02)00073-3, 2002 b.

Lehning, M., Völksch, I., Gustafsson, D., Nguyen, T. A., Stähli, M., and Zappa, M.: ALPINE3D: a detailed model of mountain surface processes and its application to snow hydrology, Hydrol. Process., 20, 2111-2128, doi:10.1002/hyp.6204, 2006.

Lehning, M., Löwe, H., Ryser, M., and Raderschall, N.: Inhomogeneous precipitation distribution and snow transport in steep terrain, Water Resour. Res., 44, W07404, doi:10.1029/2007WR006545, 2008.

LeVeque, R. J.: Finite volume methods for hyperbolic problems, Cambridge University Press, 2002.

Lippman, S. B., Lajoie, J., and Moo, B. E.: C++ Primer, 5th Edn., Addison-Wesley, 2012.

Loinaz, M. C., Davidsen, H. K., Butts, M., and Bauer-Gottwein, P.: Integrated flow and temperature modeling at the catchment scale, J. Hydrol., 495, 238-251, doi:10.1016/j.jhydrol.2013.04.039, 2013.

Lowney, C. L.: Stream temperature variation in regulated rivers: Evidence for a spatial pattern in daily minimum and maximum magnitudes, Water Resour. Res., 36, 2947-2955, doi:10.1029/2000WR900142, 2000.

MacDonald, R. J., Boon, S., and Byrne, J. M.: A process-based stream temperature modelling approach for mountain regions, J. Hydrol., 511, 920-931, doi:10.1016/j.jhydrol.2014.02.009, 2014.

Magnusson, J., Jonas, T., and Kirchner, J. W.: Temperature dynamics of a proglacial stream: Identifying domi- 
nant energy balance components and inferring spatially integrated hydraulic geometry, Water Resour. Res., 48, W06510, doi:10.1029/2011WR011378, 2012.

Majone, B., Villa, F., Deidda, R., and Bellin, A.: Impact of climate change and water use policies on hydropower potential in the south-eastern Alpine region, Sci. Total Environ., 543, Part B, 965-980, doi:10.1016/j.scitotenv.2015.05.009, 2016.

Mohseni, O., Stefan, H. G., and Erickson, T. R.: A nonlinear regression model for weekly stream temperatures, Water Resour. Res., 34, 2685-2692, doi:10.1029/98WR01877, 1998.

Moore, R. D., Sutherland, P., Gomi, T., and Dhakal, A.: Thermal regime of a headwater stream within a clear-cut, coastal British Columbia, Canada, Hydrol. Process., 19, 2591-2608, doi:10.1002/hyp.5733, 2005.

Morrison, J., Quick, M. C., and Foreman, M. G.: Climate change in the Fraser River watershed: flow and temperature projections, J. Hydrol., 263, 230-244, doi:10.1016/S0022-1694(02)00065-3, 2002.

Mott, R. and Lehning, M.: Meteorological modeling of very highresolution wind fields and snow deposition for mountains, J. Hydrometeorol., 11, 934-949, doi:10.1175/2010JHM1216.1, 2010.

Mott, R., Scipión, D., Schneebeli, M., Dawes, N., Berne, A., and Lehning, M.: Orographic effects on snow deposition patterns in mountainous terrain, J. Geophys. Res.-Atmos., 119, 1419-1439, doi:10.1002/2013JD019880, 2014.

Nash, J. and Sutcliffe, J.: River flow forecasting through conceptual models part I - A discussion of principles, J. Hydrol., 10, 282290, doi:10.1016/0022-1694(70)90255-6, 1970.

Null, S. E., Viers, J. H., Deas, M. L., Tanaka, S. K., and Mount, J. F.: Stream temperature sensitivity to climate warming in California's Sierra Nevada: impacts to coldwater habitat, Climatic Change, 116, 149-170, doi:10.1007/s10584-012-0459-8, 2013.

Padilla, A., Rasouli, K., and Déry, S. J.: Impacts of variability and trends in runoff and water temperature on salmon migration in the Fraser River Basin, Canada, Hydrol. Sci. J., 60, 523-533, doi:10.1080/02626667.2014.892602, 2015.

Phillips, J. and Tadayon, S.: Selection of Manning's roughness coefficient for natural and constructed vegetated and non-vegetated channels, and vegetation maintenance plan guidelines for vegetated channels in central Arizona, Tech. Rep. Scientic Investigations Report 2006-5108, U.S. Geological Survey, Reston, Virginia, USA, 2006.

Piccolroaz, S., Calamita, E., Majone, B., Gallice, A., Siviglia, A., and Toffolon, M.: Prediction of river water temperature: a comparison between a new family of hybrid models and statistical approaches, Hydrol. Process., 30, 3901-3917, doi:10.1002/hyp.10913, 2016.

Ponce, V. and Changanti, P.: Variable-parameter MuskingumCunge method revisited, J. Hydrol., 162, 433-439, doi:10.1016/0022-1694(94)90241-0, 1994.

Ragettli, S., Cortés, G., McPhee, J., and Pellicciotti, F.: An evaluation of approaches for modelling hydrological processes in highelevation, glacierized Andean watersheds, Hydrol. Process., 28, 5674-5695, doi:10.1002/hyp.10055, 2014.

Raymond, P., Hartmann, J., Lauerwald, R., Sobek, S., McDonald, C., Hoover, M., Butman, D., Striegl, R., Mayorga, E., Humborg, C., Kortelainen, P., Dürr, H., Meybeck, M., Ciais, P., and Guth, P.: Global carbon dioxide emissions from inland waters, Nature, 503, 355-359, doi:10.1038/nature12760, 2013.
Schaefli, B. and Gupta, H. V.: Do Nash values have value?, Hydrol. Process., 21, 2075-2080, doi:10.1002/hyp.6825, 2007.

Schaefli, B., Hingray, B., and Musy, A.: Climate change and hydropower production in the Swiss Alps: quantification of potential impacts and related modelling uncertainties, Hydrol. Earth Syst. Sci., 11, 1191-1205, doi:10.5194/hess-11-11912007, 2007.

Schaefli, B., Nicótina, L., Imfeld, C., Da Ronco, P., Bertuzzo, E., and Rinaldo, A.: SEHR-ECHO v1.0: a Spatially Explicit Hydrologic Response model for ecohydrologic applications, Geosci. Model Dev., 7, 2733-2746, doi:10.5194/gmd-7-27332014, 2014.

Short, R. A. and Ward, J. V.: Macroinvertebrates of a Colorado High Mountain Stream, The Southwestern Naturalist, 25, 23-32, 1980.

Stage, S. A.: Comments on an improvement to the Brent's method, International Journal of Experimental Algorithms, 4, 1-16, 2013.

Stewart, I. T., Cayan, D. R., and Dettinger, M. D.: Changes toward Earlier Streamflow Timing across Western North America, J. Climate, 18, 1136-1155, doi:10.1175/JCLI3321.1, 2005.

Stewart, I. T., Ficklin, D. L., Carrillo, C. A., and McIntosh, R.: 21st century increases in the likelihood of extreme hydrologic conditions for the mountainous basins of the Southwestern United States, J. Hydrol., 529, Part 1, 340-353, doi:10.1016/j.jhydrol.2015.07.043, 2015.

St-Hilaire, A., Morin, G., El-Jabi, N., and Caissie, D.: Water temperature modelling in a small forested stream: implication of forest canopy and soil temperature, Can. J. Civil Eng., 27, 10951108, doi:10.1139/100-021, 2000.

Sullivan, K., Tooley, J., Doughty, K., Caldwell, J., and Knudsen, P.: Evaluation of prediction models and characterization of stream temperature regimes in Washington, Tech. Rep. Timber/Fish/Wildlife Rep. No. TFW-WQ3-90-006, Washington Dept. Nat. Resources, Olympia, Washington, 1990.

Sun, N., Yearsley, J., Voisin, N., and Lettenmaier, D. P.: A spatially distributed model for the assessment of land use impacts on stream temperature in small urban watersheds, Hydrol. Process., 29, 2331-2345, doi:10.1002/hyp.10363, 2015.

Tang, X., Knight, D. W., and Samuels, P. G.: Variable parameter Muskingum-Cunge method for flood routing in a compound channel, J. Hydraul. Res., 37, 591-614, doi:10.1080/00221689909498519, 1999.

Tarboton, D. G.: A new method for the determination of flow directions and upslope areas in grid digital elevation models, Water Resour. Res., 33, 309-319, doi:10.1029/96WR03137, 1997.

Toffolon, M. and Piccolroaz, S.: A hybrid model for river water temperature as a function of air temperature and discharge, Environ. Res. Lett., 10, 114011, doi:10.1088/1748-9326/10/11/114011, 2015.

Tung, C.-P., Lee, T.-Y., Huang, J.-C., Perng, P.-W., Kao, S.-J., and Liao, L.-Y.: The development of stream temperature model in a mountainous river of Taiwan, Environ. Monit. Assess., 186, 7489-7503, doi:10.1007/s10661-014-3942-z, 2014.

van Beek, L. P. H., Eikelboom, T., van Vliet, M. T. H., and Bierkens, M. F. P.: A physically based model of global freshwater surface temperature, Water Resour. Res., 48, W09530, doi:10.1029/2012WR011819, 2012.

van Heesch, D.: Doxygen: Source code documentation generator tool, available at: http://www.doxygen.org/ (last access: 24 February 2014), 2008. 
van Vliet, M. T. H., Yearsley, J. R., Franssen, W. H. P., Ludwig, F., Haddeland, I., Lettenmaier, D. P., and Kabat, P.: Coupled daily streamflow and water temperature modelling in large river basins, Hydrol. Earth Syst. Sci., 16, 4303-4321, doi:10.5194/hess-16-4303-2012, 2012.

Viviroli, D., Archer, D. R., Buytaert, W., Fowler, H. J., Greenwood, G. B., Hamlet, A. F., Huang, Y., Koboltschnig, G., Litaor, M. I., López-Moreno, J. I., Lorentz, S., Schädler, B., Schreier, H., Schwaiger, K., Vuille, M., and Woods, R.: Climate change and mountain water resources: overview and recommendations for research, management and policy, Hydrol. Earth Syst. Sci., 15, 471-504, doi:10.5194/hess-15-471-2011, 2011.

Voegeli, C., Lehning, M., Wever, N., and Bavay, M.: Scaling precipitation input to distributed hydrological models by measured snow distribution, Front. Earth Sci., in preparation, 2016.

Vrugt, J. A. and Ter Braak, C. J. F.: $\operatorname{DREAM}_{(\mathrm{D})}$ : an adaptive Markov Chain Monte Carlo simulation algorithm to solve discrete, noncontinuous, and combinatorial posterior parameter estimation problems, Hydrol. Earth Syst. Sci., 15, 3701-3713, doi:10.5194/hess-15-3701-2011, 2011.

Webb, B. W. and Zhang, Y.: Spatial and seasonal variability in the components of the river heat budget, Hydrol. Process., 11, 79-101, doi:10.1002/(SICI)1099-1085(199701)11:1<79::AIDHYP404>3.0.CO;2-N, 1997.

Wehrly, K. E., Wang, L., and Mitro, M.: Field-Based Estimates of Thermal Tolerance Limits for Trout: Incorporating Exposure Time and Temperature Fluctuation, T. Am. Fish. Soc., 136, 365374, doi:10.1577/T06-163.1, 2007.
Weijs, S. V., Mutzner, R., and Parlange, M. B.: Could electrical conductivity replace water level in rating curves for alpine streams?, Water Resour. Res., 49, 343-351, doi:10.1029/2012WR012181, 2013.

Westhoff, M. C., Savenije, H. H. G., Luxemburg, W. M. J., Stelling, G. S., van de Giesen, N. C., Selker, J. S., Pfister, L., and Uhlenbrook, S.: A distributed stream temperature model using high resolution temperature observations, Hydrol. Earth Syst. Sci., 11, 1469-1480, doi:10.5194/hess-11-1469-2007, 2007.

Wever, N., Fierz, C., Mitterer, C., Hirashima, H., and Lehning, M.: Solving Richards Equation for snow improves snowpack meltwater runoff estimations in detailed multi-layer snowpack model, The Cryosphere, 8, 257-274, doi:10.5194/tc-8-257-2014, 2014.

Wever, N., Schmid, L., Heilig, A., Eisen, O., Fierz, C., and Lehning, M.: Verification of the multi-layer SNOWPACK model with different water transport schemes, The Cryosphere, 9, 2271-2293, doi:10.5194/tc-9-2271-2015, 2015.

Wilhelm, L., Besemer, K., Fragner, L., Peter, H., Weckwerth, W., and Battin, T.: Altitudinal patterns of diversity and functional traits of metabolically active microorganisms in stream biofilms, ISME Journal, 9, 2454-2464, doi:10.1038/ismej.2015.56, 2015.

Zappa, M., Pos, F., Strasser, U., Warmerdam, P., and Gurtz, J.: Seasonal Water Balance of an Alpine Catchment as Evaluated by Different Methods for Spatially Distributed Snowmelt Modelling, Hydrol. Res., 34, 179-202, 2003.

Zeng, X.: A general approach to enhance slope limiters on nonuniform rectilinear grids, arXiv:1301.0967, available at: http:// arxiv.org/abs/1301.0967, 2013. 